\title{
PROBABILISTIC POWER TRANSMISSION SYSTEM RELIABILITY EVALUATION
}

\author{
by \\ Saeid Biglary Makvand, \\ B.Sc, Ryerson University, Toronto, Canada, 2012
}

A thesis presented to Ryerson University in partial fulfillment of the requirements for the degree of Master of Applied Science in the program of Electrical and Computer Engineering

Toronto, Ontario, Canada, 2014

(C) Saeid Biglary Makvand, 2014 
I hereby declare that I am the sole author of this thesis. This is a true copy of the thesis, including any required final revisions, as accepted by my examiners.

I authorize Ryerson University to lend this thesis to other institutions or individuals for the purpose of scholarly research.

I further authorize Ryerson University to reproduce this thesis by photocopying or by other means, in total or in part, at the request of other institutions or individuals for the purpose of scholarly research.

I understand that my thesis may be made electronically available to the public. 


\title{
Abstract
}

\section{PROBABILISTIC POWER TRANSMISSION SYSTEM RELIABILITY EVALUATION}

\author{
Master of Applied Science, 2014 \\ Saeid Biglary Makvand \\ Computer and Electrical Engineering program, Ryerson University
}

Modern power systems are prudently designed and operated to their brim as allowed by policies and procedures. Many of these utilities have advanced transmission systems built over half a century. With considerable aging transmission asset, their up keep and renewal is very expensive. Probabilistic planning, though computationally cumbersome, is an approach that objectively compares economic risk from aging assets versus cost of upgrades. With a demand for such a generic tool amongst utilities, this thesis presents a probabilistic approach for transmission system expansion planning. The proposed method estimates potential economic losses from aging transmission system assets considering N-1 contingencies where N-1 contingencies represent operation of the transmission system after one element is removed due to fault. Thereafter, the thesis proposes a formulation that computes the best transmission system reinforcement plan to eliminate economic losses from all possible $\mathrm{N}-1$ contingencies.

Finally, tests on a sample 7-bus system and IEEE 118-bus system where potential economic losses from $\mathrm{N}-1$ contingencies is compared with transmission system optimal expansion plan are presented. Test results reveal that in certain cases, there is economic merit to upgrade the system and benefit with from a robust transmission system. A 304-bus North American system was also tested and is reported. 


\section{Acknowledgements}

I would like to thank my supervisor Dr. Bala Venkatesh for his help and guidance in completing this thesis. I would also like to thank Dr. Daniel Cheng for his assistance. 


\section{Contents}

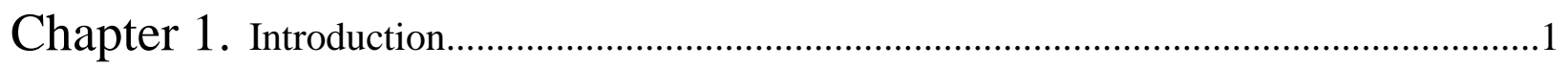

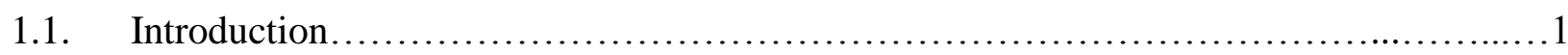

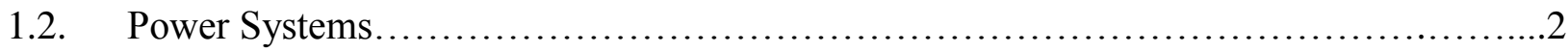

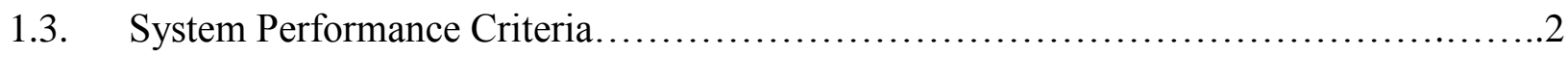

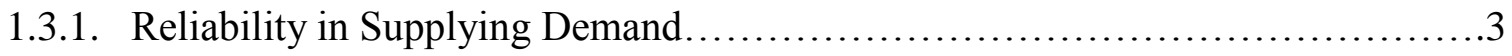

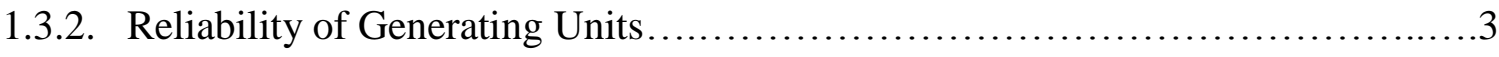

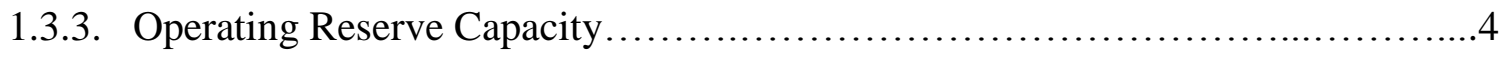

1.3.4. Reliability of Transmission Components...................................4

1.3.5. Amount of Power Loss Due to Transfer of Electricity from Generator to Load....5

1.3.6. System Voltage Fluctuations..............................................5

1.3.7. Quality of Delivered Power.............................................6

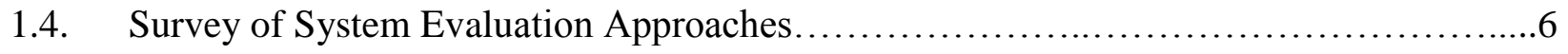

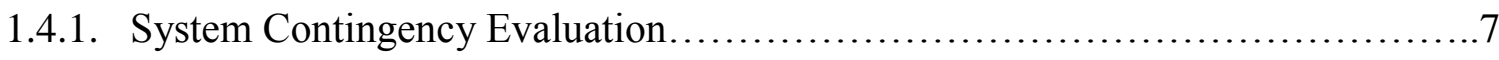

1.4.2. Voltage Stability Evaluation............................................... 10

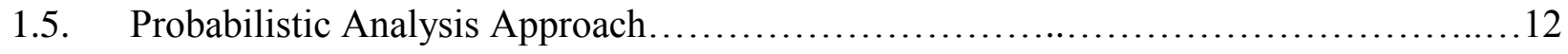

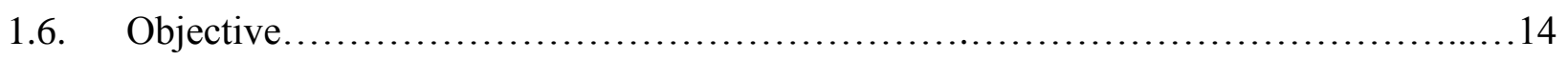

Chapter 2. EENS Cost Probabilistic Reliability Index........................................................16

2.1. Routine Used to Find EENS Cost Index ..................................................................

2.2. Optimal Power Flow Used to Find EENS Cost Index.....................................................19

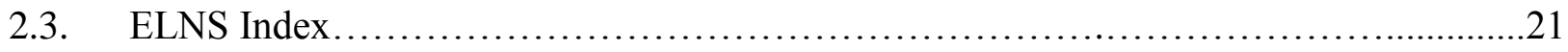


2.4. EENS Determination for Example Case.

Chapter 3. Probabilistic Routines Providing Optimal System Upgrade Suggestions .27

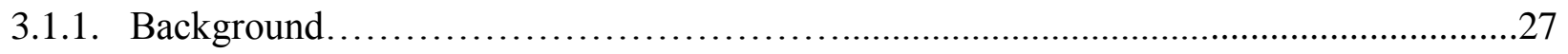

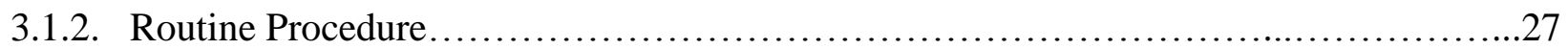

3.1.3. Optimal Power Flow Used in Branch/Transformer Upgrade Suggestion Routine.............35

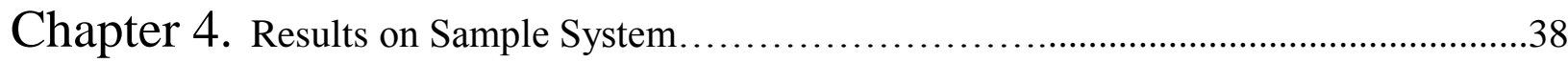

4.1. Data Used for Upgrade Cost Estimates...............................................38

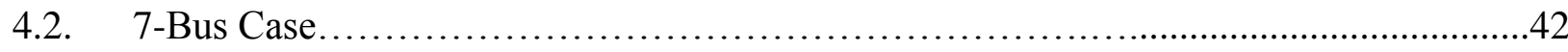

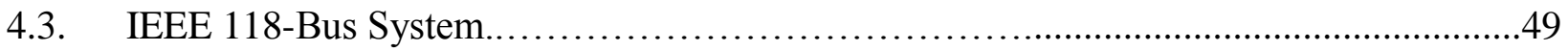

4.4. A North American System Data.....................................................53

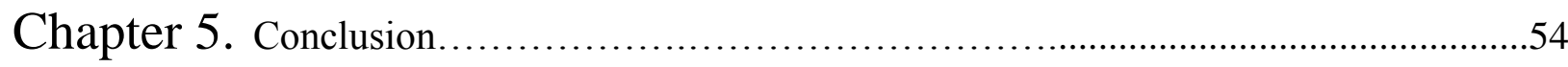

5.1. Summary of Work Done in the Thesis..........................................54

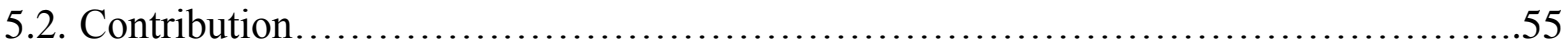

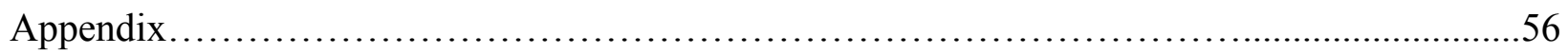

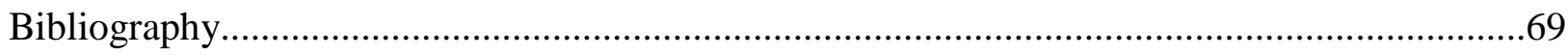




\section{List of Tables}

Table 1: Minimum load shedding OPF results on 4 bus system...........................24

Table 2: Minimum load shedding OPF results on modified 4 bus system...................26

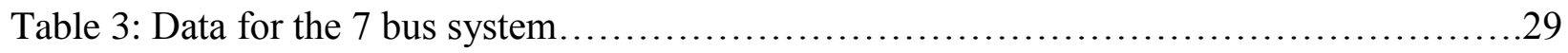

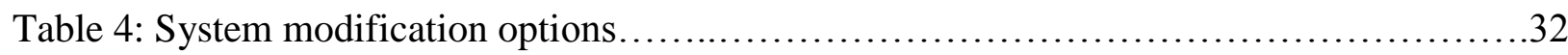

Table 5: Results used to provide upgrade suggestions................................ 34

Table 6: Transmission and substation facilities included in the study.........................39

Table 7: Transmission capital cost summary........................................40

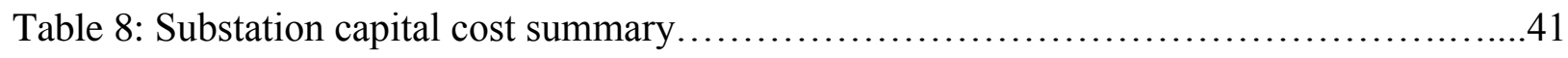

Table 9: 'EENS Cost' results for original and variations of system under study................43

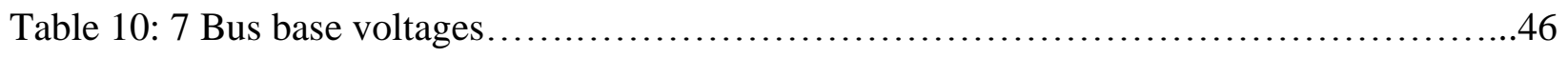

Table 11: 7 Bus branch connection lengths.......................................46

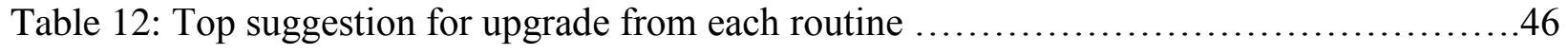

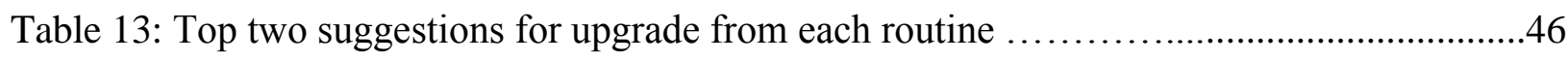

Table 14: Reliability index values of re-enforced 7 bus system using top routine suggestions....47

Table 15: Reliability index values of re-enforced 7 bus system using top two routine

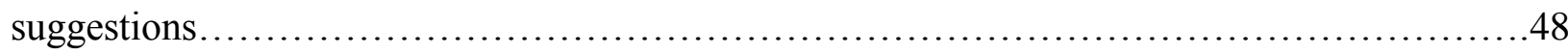

Table 16: 'EENS Cost' results for original and variations of system under study ..............50

Table 17: Top three suggestion for upgrade from each routine............................51

Table 18: Reliability index values of systems ....................................51 


\section{List of Figures}

Figure 1: Contingency Sensitivity Index calculation routine $\ldots \ldots \ldots \ldots \ldots \ldots \ldots \ldots \ldots \ldots \ldots$

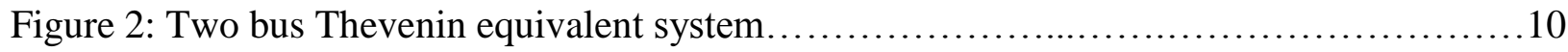

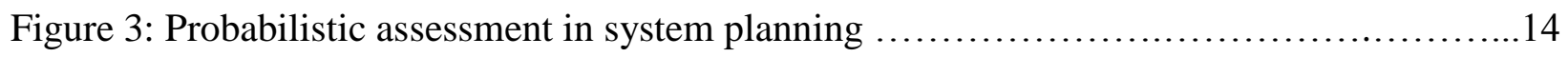

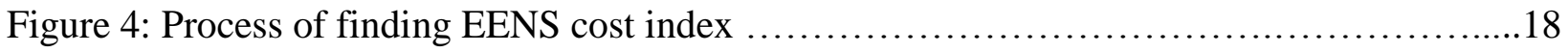

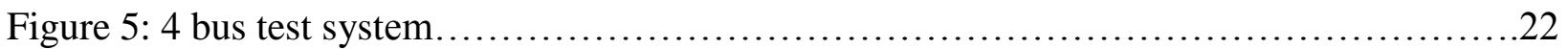

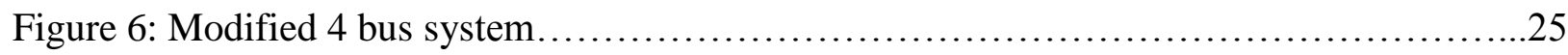

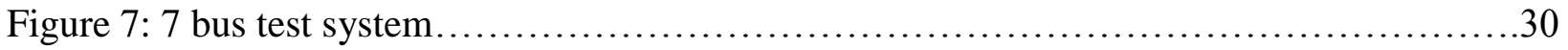




\section{Nomenclature}

EENS

ELNS

OPF

$\mathrm{PD}_{\mathrm{i}}$

$\mathrm{QD}_{\mathrm{i}}$

$\mathrm{PG}_{\mathrm{i}}$

$\mathrm{QG}_{\mathrm{i}}$

$\mathrm{PS}_{\mathrm{i}}$

$\mathrm{QS}_{\mathrm{i}}$

$\mathrm{P}_{\mathrm{i}}$

$\mathrm{Q}_{\mathrm{i}}$

NL

NC

$\mathrm{V}_{\mathrm{i}} \angle \delta_{\mathrm{i}}$

$\mathrm{Y} \angle \theta$
Expected Energy Not Supplied

Expected Load Not Supplied

Optimal Power Flow

Real load at bus i

Reactive load at bus i

Real generation at bus $i$

Reactive generation at bus $\mathrm{i}$

Real load shed at bus $\mathrm{i}$

Reactive load shed at bus $i$

Calculated real power at bus $\mathrm{i}$

Calculated reactive power at bus i

Number of load buses

Number of lines or transformers

Voltage phasor of bus $i$

Bus Admittance Matrix 
$\mathrm{S}_{\mathrm{ik}}$

$\mathrm{SU}_{\mathrm{ik}}$

$\mathrm{UDS}_{\mathrm{ik}}$

$\mathrm{N}$

c
Apparent power flow from bus I to bus $\mathrm{k}$

Upgrade in MVA capacity of line bus i to bus $\mathrm{k}$

Upgrade difficulty of line bus i to bus $\mathrm{k}$

Number of contingencies

Contingency number 


\section{Chapter 1 - Introduction}

\subsection{Introduction}

Transmission systems transmit electric energy over long distances and usually have a mesh topology. Generators supply energy that is transmitted via transmission systems to reach distribution systems for supplying to customers. Transmission systems comprise of transmission lines and transformers, and total to $\mathrm{N}$ elements. In classical power systems, transmission systems are $\mathrm{N}-1$ reliable whereby should any one of the $\mathrm{N}$ transmission elements suffer a fault, remaining $\mathrm{N}-1$ elements should be sufficient to transmit energy from generators to all connected customers. High degree of reliability means that the system has redundancy. Higher the reliability, higher is the redundancy leading to an expensive transmission system. Power system planners grapple with the challenge of prudent design such that the transmission system is reliable meeting required standard whilst costing the least.

To design, assess or reinforce electric power systems various evaluation approaches need to be formulated to compare the different design options and choose the best one. These formulations must be developed based on the performance criteria and the aspect of the system that needs to be analyzed, such as N-1 criterion. Other than formulating approaches for assessment of systems, development of routines and procedures which provide suggestions on system reinforcements to improve the performance of the system in the assessed area is also needed. This is due to the complexity of electric systems where manual determination of optimum system reinforcements 
is not possible. Based on these needs, power system assessment approaches and procedures to determine optimal system reinforcements were formulated.

\subsection{Power Systems}

The construction and operation of electrical power systems is a complicated and evolving task that continues to change. What started as a single generator supplying a small load has today evolved into large interconnected power systems comprising different countries as well as continents. As the systems evolved through past decades system designers and operators have improved their performance and reliability through extensive studies as well as the experience and knowledge gained from operation of these systems. The analysis of power systems takes on a wide range of areas ranging from small scale performance evaluation of individual system components such as circuit breakers or relays to large scale analysis of the entire systems response to a significant contingency. The focus of this thesis is on the relatively larger scale evaluation of systems. An overview of several power system performance criteria followed by some recent assessment approaches are given below.

\subsection{System Performance Criteria}

The relative performance of electric systems can be assessed in a wide range of areas. Listed below are possible criteria when assessing electric system's performance. 


\subsubsection{Reliability in Supplying Demand}

One of the main aspects of system performance is its capacity in supplying the power demand. While in theory systems are designed to constantly supply the demand, in actual system operation electric supply may be cut off from all or a portion of consumers by the operator due to varying reasons such as reduced system generation capacity, forced transmission system component outage, unexpected rise in electricity demand, voltage limit violations, transmission line overflows, etc. Different indices and approaches can be developed to assess this aspect of the system such as the Loss of Load Probability index, which gives the probability of demand exceeding generation capacity for a given interval [1].

\subsubsection{Reliability of Generating Units}

Depending on the size and configuration of an electric system, a number of generating units are placed in optimum locations. The system operator optimally utilizes these available sources to supply system demand. Assessment of a system may involve performance evaluation of these generating units in aspects such as reliability of generation, cost of generation, ramping rate, etc. The area of generating unit reliability has become more complicated with the move to smart grids which contain renewable sources such as wind and solar energy. Unlike the traditional generators, the exact output and reliability of these sources is more complicated. System designers will need to take new approaches in modeling and analysis of generating units in the future grid. 


\subsubsection{Operating Reserve Capacity}

Other than the scheduled generation in system operation, backup generation capacity is also present. This capacity falls into the spinning reserve and non-spinning reserve category. The former is the capacity of online generating units to vary their output according to unpredictable relatively small variations in load, while the latter is constitutes other offline generating units which may be utilized if required. The non-spinning reserve amount usually depends on output of largest generating unit or the peak load of the system. With the integration of renewable such as wind powered generation, the spinning reserve capacity of systems has been affected due to the lower spinning capacity of these units [2].

\subsubsection{Reliability of Transmission Components}

Sufficient generating capacity requires a reliable transmission network to supply the consumers. The outage of one component of the transmission network may be sufficient to disrupt system operation. Other than assessment of a systems generating unit capability, the analysis of transmission elements used to deliver the generated power is another major area in system performance evaluation. For example, a system may be assessed by determining the critical transmission components of the system based on their impact on regular operation. The impact of outage of these components may be analyzed in terms of their affect on system stability, voltage levels, supplying system loads, etc. By determining the critical components and their impact, system designers can re-enforce these elements and improve reliability. 


\subsubsection{Amount of Power Loss Due to Transfer of Electricity from Generator to Load}

The transfer of electric power from generating sources through transmission and distribution sectors to the final consumer results in loss of energy due to causes such as heated transmission cables. While the transfer of real power causes system losses, the real power losses are also attributed to the transmission of reactive power. The losses depend on the route the generated power from source units takes to arrive at the load which is determined by the operator based on system configuration, connection flow limits, available generating units, voltage limits, etc. Designers consider this aspect of system operation when evaluating system reliability. For example, different system configurations may be able to supply consumer loads sufficiently, but at varying loss levels. Hence, when various system configurations are available for implementation, assessing their corresponding energy loss may provide the optimum approach.

\subsubsection{System Voltage Fluctuations}

The proper operation of loads is dependent on the voltage levels of system buses. Voltage violations may occur due to reasons such as improper scheduling of generating bus voltages which determine the load bus voltages or excessive increase in demand which may result in brownouts. Voltage violations may harm system components. For example, high voltages may damage appliances while low voltages can harm electric motors. Containing the voltages throughout the system within acceptable limits is an integral part of its operation. The system 
operator does so through proper scheduling of generating units resulting in an acceptable load flow solution and utilization of shunt elements, transformer tap ratios, etc. when voltage violations occur in the system [1].

\subsubsection{Quality of Delivered Power}

The loads in electric systems are designed to operate using an ideal voltage signal. In AC electric systems, the ideal voltage would have a sinusoidal form with deviations only in angle and magnitudes throughout the system where required. This is not the case due to various factors including the nonlinear nature of system components such as the transmission lines and transformers which cause deviations in voltage and current signals even if ideal signals are generated at generating stations. The main cause of unwanted harmonics in system signals which has been increasing in recent decades are nonlinear loads in the system. The reason for this is the increasing use of power electronic components in system loads. System designers control system harmonics through measures such as filter installations as well as imposing limits on harmonic generating loads in the system [3].

\subsection{Survey of System Evaluation Approaches}

Before discussing the proposed system evaluation and improvement approaches, a survey of assessment approaches are given below followed by an explanation of probabilistic system planning. 
The indicating factors in the performance of an electric system were discussed in the first chapter. System designers must consider these to varying degrees when designing or improving existing systems. The importance of mentioned system parameters depends on the system under study determined by for example imposed government regulations or economic incentives of private companies. Varying approaches may be implemented to provide an estimation of the performance of the system in these fields. Some recent approaches are explained below to give an idea of system assessment methods.

\subsubsection{System Contingency Evaluation}

Assessment of contingencies in a power system and their varying impact on regular operation is crucial in system operation. Contingencies may have no significant impact on system operation or on the other hand may impact voltage stability, generation capacity, etc. Reference [4] provides a contingency ranking method. The developed routine provides an assessment of the economic impact of contingencies on the power system. The variation of the Locational Marginal Price (LMP) of each system bus in the post-contingency configuration is calculated and used to derive an estimation of the economic impact of contingencies. The Locational Marginal

Price is the amount consumers must pay for energy in various regions of the system. This parameter depends on the costs of energy, losses incurred due to transfer of energy as well as congestion and is given in (1) taken from [4].

$$
L M P_{i}=L M P_{\text {energy }}+L M P_{\text {loss }}+L M P_{\text {congestion }}
$$


An optimal power flow formulation is used to derive the LMP in pre and post contingency conditions. Once the LMPs are obtained, a Contingency Sensitivity Index (CSI) is calculated for each contingency, as shown in (2) taken from [4].

$$
\operatorname{CSI}\left(N_{b}, k\right)=\sum_{i=1}^{N_{b}} w_{i}\left|L M P_{S i}^{k}-L M P_{S i}^{0}\right|
$$

In (2), $\mathrm{N}_{\mathrm{b}}$ is the number of buses, $\mathrm{k}$ is the contingency number, $\mathrm{w}_{\mathrm{i}}$ is the scale which represents the importance of each bus I and the two LMP numbers are the pre and post contingency costs for each bus. In this manner, by calculating the CSI index for all contingencies, their relative impact on system operation can be compared. The routine used to find this index is shown in Fig. 1 taken from [4]. 


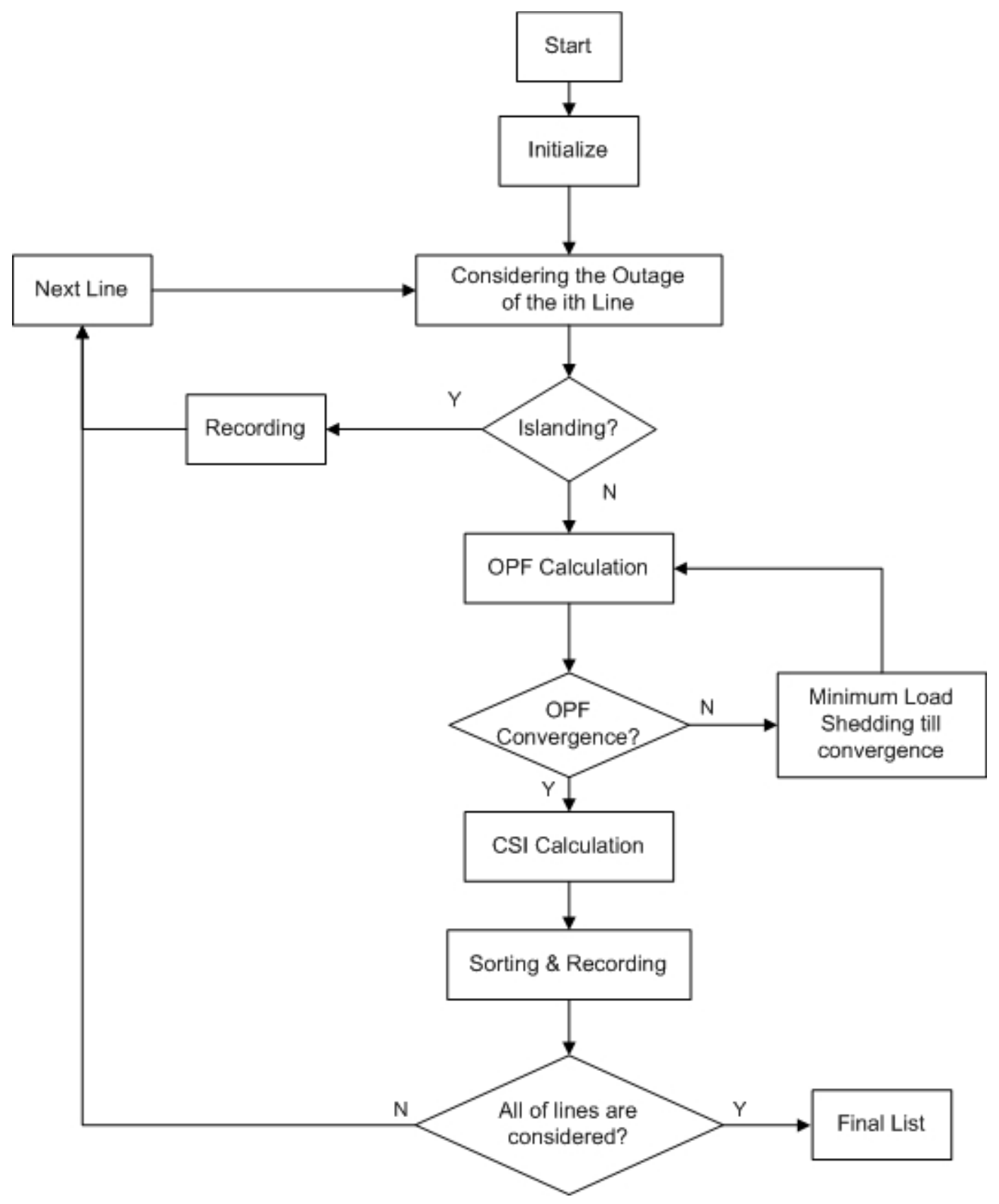

Fig. 1. Contingency Sensitivity Index calculation routine [4]. 


\subsubsection{Voltage Stability Evaluation}

As stated previously, the power system requires voltage stability for its operation. A possible approach in providing insight into the voltage stability of an existing or future system is assessment of the stability of individual buses provided estimates of system parameters such as expected load levels. Such an approach is explained in [5]. An index called Power Transfer Stability Index (PTSI) is developed for each bus of the system. The index is obtained by modeling each bus as a Thevenin circuit where the slack bus is connected to a load bus as shown in Fig. 2 taken from [5].

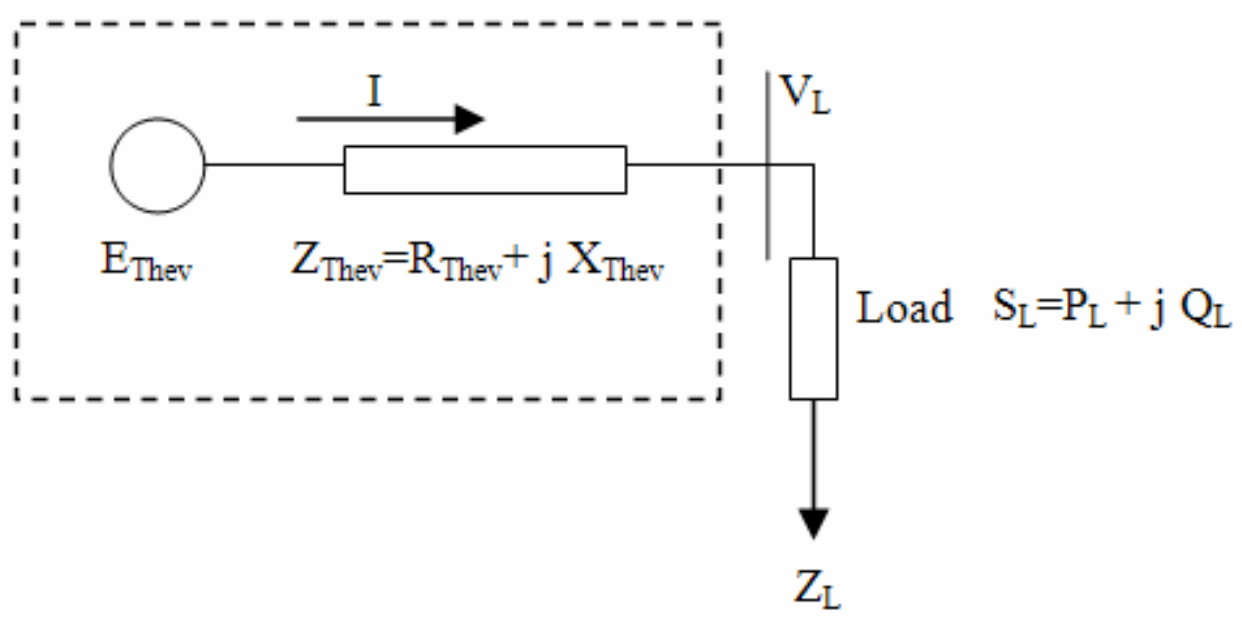

Fig. 2. Two bus Thevenin equivalent system [5].

The loss of voltage stability at each bus can be said to be dependent on the drawn power $\mathrm{S}_{\mathrm{L}}$ of each load. The drawn power can be written as in (3) taken from [5]. 


$$
\bar{S}_{L}=\bar{Z}_{L}|\bar{I}|^{2}=\bar{Z}_{L}\left|\frac{\bar{E}_{\text {Thev }}}{\bar{Z}_{\text {Thev }}+\bar{Z}_{L}}\right|^{2}
$$

The magnitude of this apparent power given in [5] can be expressed as shown in (4).

$$
S_{L}=\frac{E_{\text {Thev }}^{2} Z_{L}}{\left|Z_{\text {Thev }}<\beta+Z_{L}<\alpha\right|^{2}}=\frac{E_{\text {Thev }}^{2} Z_{L}}{Z_{\text {Thev }}^{2}+Z_{L}^{2}+2 Z_{\text {Thev }} Z_{L} \cos (\beta-\alpha)}
$$

The maximum value of $S_{L}$ can be obtained by calculation of the derivative of $S_{L}$ with respect to $\mathrm{Z}_{\mathrm{L}}$ and equating this expression to zero. This would result in $\mathrm{S}_{\mathrm{L} \text { max }}$ shown in (5) taken from [5].

$$
S_{L \max }=\frac{E_{\text {Thev }}^{2}}{2 Z_{\text {Thev }}(1+2 \cos (\beta-\alpha))}
$$

Using the expressions for $S_{\mathrm{L}}$ and $\mathrm{S}_{\mathrm{L} \max }$, an index can be obtained to show the proximity of each bus to voltage collapse conditions given the operating conditions of the system. This index is the ratio of $S_{L}$ to $S_{L \max }$, shown in (6) taken from [5].

$$
\text { PTSI }=\frac{S_{L}}{S_{L \max }}=\frac{2 S_{L} Z_{\text {Thev }}(1+2 \cos (\beta-\alpha))}{E_{\text {Thev }}^{2}}
$$

Using (6), the range of PTSI will be from 0 to 1 , with higher values indicating closer proximity to voltage collapse conditions. Given the operating conditions of a specific system, the PTSI index can be calculated for all the load buses to obtain an insight into the voltage stability of the system. 


\subsection{Probabilistic Analysis Approach}

As stated, electric power transmission systems are designed and expanded to satisfy reliability criteria set by the regulatory agencies. Typically, transmission systems are designed to withstand $\mathrm{N}-1$ and select $\mathrm{N}-2$ contingencies. In this case, the transmission system would survive outage of a line or a transformer outage and continue to supply customers.

Several deterministic transmission system expansion planning methods have been presented in the literature. The drawback of deterministic approaches is that the probabilistic nature of power system contingencies is not considered and results in a transmission system expansion plan that is very expensive. As a simple example, there may be an $\mathrm{N}-1$ contingency with a relatively low occurrence as opposed to an N-3 scenario with a relatively higher occurrence probability and significant impact on the system operation for a system under study.

That said, it is computationally very cumbersome to undertake probabilistic transmission system expansion planning. To articulate, consider a transmission system with 500 elements. In that case, number of N-1 cases would be 500 and number of N-2 cases would equal 125,000 . The number of N-3 scenarios would amount to approximately 21 million.

With the continued advancement in available computation tools, speed of computers and memory capacities, it is becoming possible to undertake probabilistic transmission system expansion planning. Another impediment in using probabilistic transmission system expansion planning methods can be attributed to lack of required system data. These may include 
probabilistic data such as failure frequency and failure duration representing the behavior of system components such as transmission lines, transformers, generating units, shunt elements, circuit breakers, system switches, etc. Lack of data has become less of an obstacle with the increased monitoring of transmission systems with the advent of smart grids as well as the advancements in modeling of system components.

The goal of probabilistic transmission system expansion planning is to utilize probabilistic aspects of the system performance and develop an optimal expansion plan such that probability of loss of load considering N-1 and select N-2 contingencies is eliminated at the least cost. Such approaches have been assessed in recent years by using probabilistic aspects of the transmission system such as line/generator outage rates, generating units ramp costs and the wide possible range of system states (the state depending on load levels, generation capacity, etc.) to obtain reliability indices and the optimum system design in terms of construction costs, outage costs, dispatch costs, etc. The flowchart in Fig. 3 shows the use of probabilistic assessment in system planning [6]. 


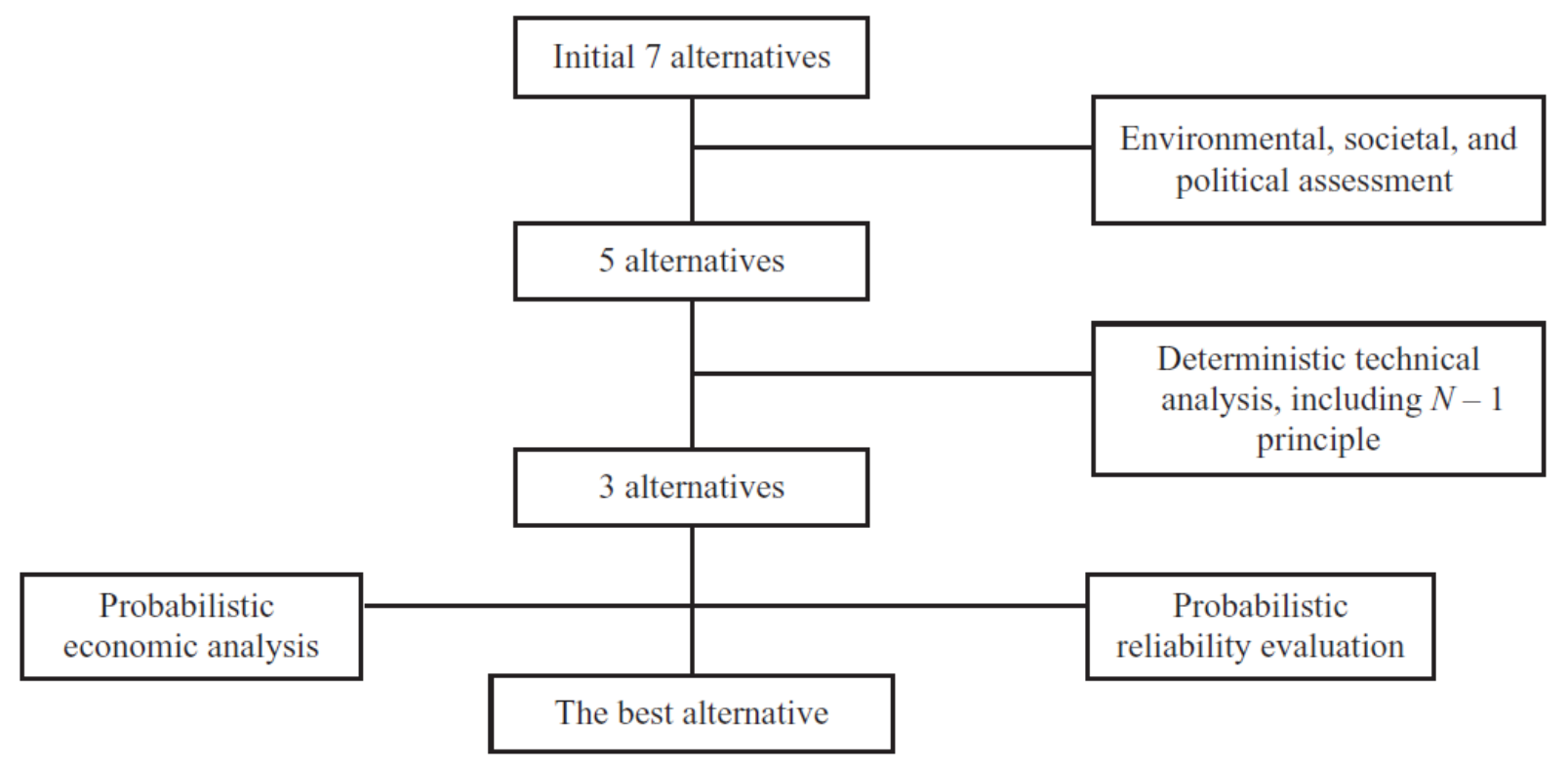

Fig. 3. Probabilistic assessment in system planning [6].

\subsection{Objective}

The main aim of this thesis is to propose approaches in power system evaluation and improvement. This is done while incorporating a new aspect in system planning, namely probabilistic system analysis which was explained previously. After studying various criteria used to evaluate electric systems, the economic aspect of the system performance was chosen as the assessment criteria. The economic performance of the system under study is evaluated by estimating the cost of the expected energy not supplied for a projected year. Using this reliability index, the performance of a system and variations of that system can be computed and compared. Due to the complexity of large electric systems, manual determination of the optimum system reinforcement is not possible. Therefore a new routine is proposed which determines the optimum system reinforcement to improve system reliability. Since increasing the MVA rating 
limits of system connections is a common approach for system reinforcement, the routines were developed to provide suggestions on which transformer/branch connections to upgrade to improve system reliability. These formulations are then implemented using MATLAB and tested on sample and actual power systems. 


\section{Chapter 2 - EENS Cost Probabilistic Reliability Index}

Transmission systems are designed to supply connected loads and should safely operate with N-1 contingencies and certain select $\mathrm{N}-2$ as per the prevailing policies. In power systems, an N-1 contingency refers to the system state after the outage and removal of components such as a transmission line or a transformer. Higher order contingencies, such as the N-2 contingency, refer to simultaneous outage of more than one component. During N-1 and other contingencies, the system may encounter loss of load. If the failure duration and number of failures of all the contingencies over a specific period are known, the total expected energy not supplied for the system under study can be obtained for that period. This is done by first obtaining the amount of load shed for each contingency. Once this is known, the total energy not supplied for that contingency is obtained by multiplication of the shed load by the estimated duration of the contingency over the period under study. This estimated duration is multiplication of failure duration by number of failures for that period.

The estimate of loss of load presented here is the Expected Energy Not Supplied (EENS) cost for a system under study for a projected year.

\subsection{Routine Used to Find EENS Cost Index}

The process for determining the EENS cost index is shown in Fig. 4. To obtain this index, the power system load flow data including bus generation/load levels and ranges, bus voltage limits, connection flow limits and impedance values are needed. Also, the expected system 
contingencies and their frequency and mean duration for a projected year are used. The probabilistic aspects involved in arriving at this index include:

- $\quad$ The estimation of system loads.

- $\quad$ N-1 contingencies, frequency and duration for the year.

- The optimal power flow used to find the minimum required load shedding after contingencies.

- The cost assigned to EENS values, which depends on various factors including industrial, commercial or residential components of system loads. 


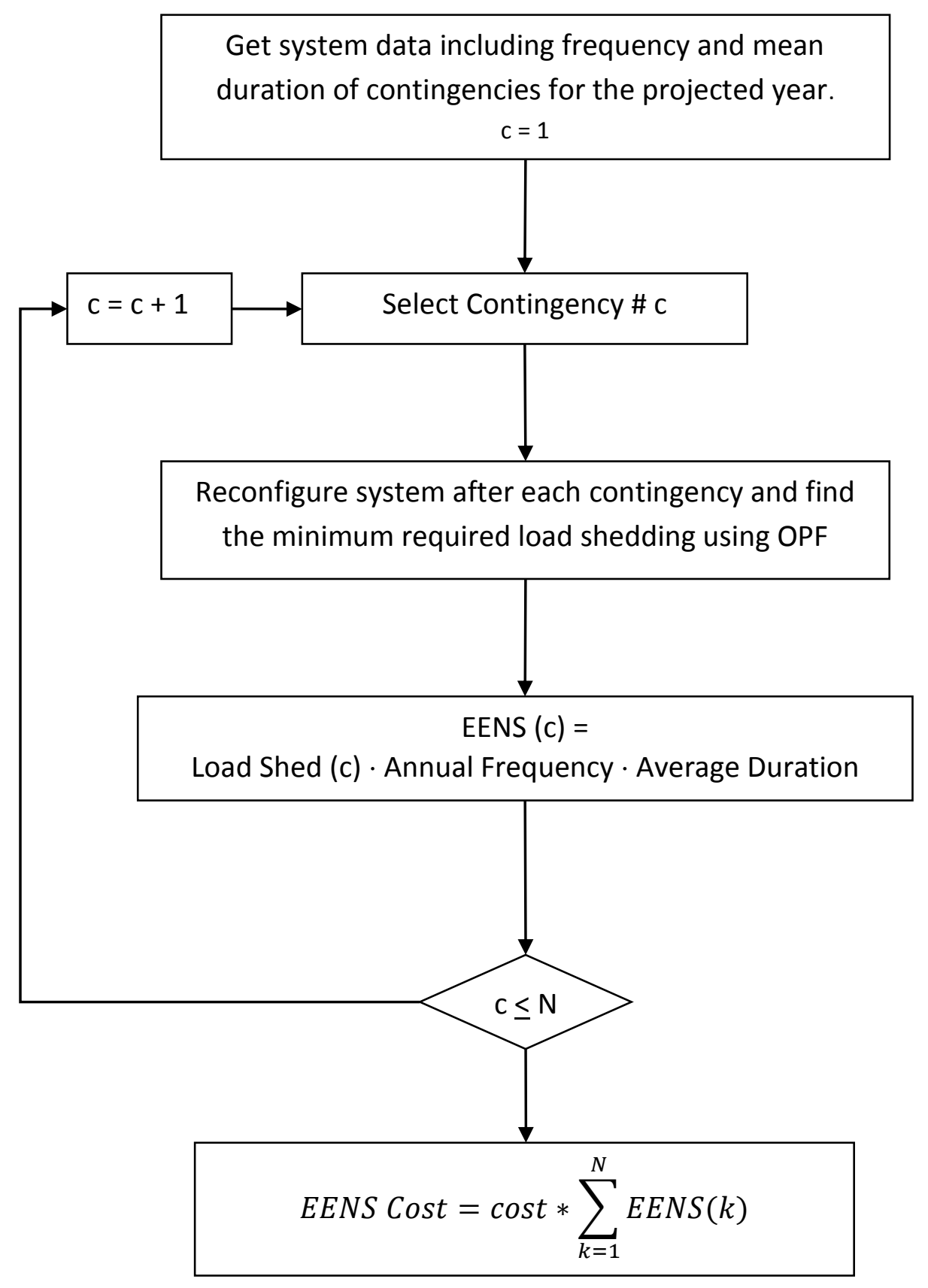

Fig. 4. Process of finding EENS cost index. 


\subsection{Optimal Power Flow Used to Find EENS Cost Index}

When an N-1 contingency occurs in a power system such as failure of transmission line or transformer connections, the transmission system is expected to continue operation while shedding the minimum load where inevitable. This contingency state operation may be constrained by voltage, generation and flow limits. The optimal power flow used to obtain the minimum required load shedding after a contingency is shown in this section.

\section{Decision and Dependent Variables}

The decision variables include Power Generation (PG and QG) and the Load Shed (PS and QS). The dependent variables used for the OPF are the bus voltage magnitudes $\left|V_{\mathrm{i}}\right|$ and angles $\delta_{\mathrm{i}}$ for all $\mathrm{i}$ buses, the calculated power at each bus $(\mathrm{P}$ and $\mathrm{Q})$ and MVA flow on transmission lines $\left(\mathrm{S}_{\mathrm{ik}}\right)$. Load (PD and QD) and system admittance matrix Y(c) are constants. For each contingency ' $\mathrm{c}$ ', the system admittance matrix is created as $\mathrm{Y}(\mathrm{c})$.

\section{Constraints}

The equality constraints arising from power balance equations are given in (7) and (8). 


$$
\begin{gathered}
\mathrm{PG}_{\mathrm{i}}+\mathrm{PS}_{\mathrm{i}}-\mathrm{PD}_{\mathrm{i}}=\mathrm{P}_{\mathrm{i}} \\
\mathrm{P}_{\mathrm{i}}=\sum_{\mathrm{k}=1}^{\mathrm{N}}\left|\mathrm{Y}_{\mathrm{ik}} \cdot \mathrm{V}_{\mathrm{i}} \cdot \mathrm{V}_{\mathrm{k}}\right| \cdot \cos \left(\delta_{\mathrm{i}}-\delta_{\mathrm{k}}-\theta_{\mathrm{ik}}\right) \\
\mathrm{QG}_{\mathrm{i}}+\mathrm{QS}_{\mathrm{i}}-\mathrm{QD}_{\mathrm{i}}=\mathrm{Q}_{\mathrm{i}} \\
\mathrm{Q}_{\mathrm{i}}=\sum_{\mathrm{k}=1}^{\mathrm{N}}\left|\mathrm{Y}_{\mathrm{ik}} \cdot \mathrm{V}_{\mathrm{i}} \cdot \mathrm{V}_{\mathrm{k}}\right| \cdot \sin \left(\delta_{\mathrm{i}}-\delta_{\mathrm{k}}-\theta_{\mathrm{ik}}\right)
\end{gathered}
$$

Line flow is computed below (9):

$$
\mathrm{S}_{\mathrm{ik}}=\mathrm{V}_{\mathrm{i}} \cdot\left[\left(\mathrm{V}_{\mathrm{i}}-\mathrm{V}_{\mathrm{k}}\right) \cdot\left(\mathrm{y}_{\mathrm{ik}}\right)\right]^{*}
$$

The formulation limits voltage magnitudes, real and reactive power generation and power flow in transmission elements. These constraints are shown in (10) to (15).

$$
\begin{gathered}
|\underline{V}|<\left|\mathrm{V}_{\mathrm{i}}\right|<|\overline{\mathrm{V}}| \\
\underline{P G}<P G<\overline{\mathrm{PG}} \\
\underline{Q G}<Q G<\overline{\mathrm{QG}} \\
\underline{\mathrm{PS}}<P S<\overline{\mathrm{PS}} \\
\underline{\mathrm{QS}}<Q S<\overline{\mathrm{QS}} \\
\left|\mathrm{S}_{\mathrm{ik}}\right|=\left|\mathrm{V}_{\mathrm{i}} \cdot\left[\left(\mathrm{V}_{\mathrm{i}}-\mathrm{V}_{\mathrm{k}}\right) \cdot\left(\mathrm{y}_{\mathrm{ik}}\right)\right]^{*}\right|<\overline{\mathrm{S}_{\mathrm{ik}}}
\end{gathered}
$$




\section{Objective Function}

The objective function to be minimized is the total reduction of loads for all buses relative to their original value. The objective function is shown in (16), where NL is the number of load buses.

$$
\text { Minimize: LoadShed }(\mathrm{c})=\sum_{\mathrm{i}=1}^{N L}\left[\mathrm{PS}_{\mathrm{i}}\right]+\sum_{\mathrm{i}=1}^{\mathrm{NL}}\left[\mathrm{QS}_{i}\right]
$$

Using (16) and (7) to (15), the minimum value of EENS for an N-1 contingency state c is determined.

\subsection{ELNS Index}

Along with the EENS cost index, the ELNS index is also computed. ELNS stands for expected load not supplied. This index is similar to the 'EENS Cost'. The only difference is that the frequency and mean duration of the contingencies are not used to find the ELNS that includes values for real and reactive load. The ELNS is given as an output of the tool to show the relative reliability of different system configurations in terms of load shedding for selected contingencies, in case there is uncertainty regarding the contingency frequency and duration and the cost of energy not supplied values which are used to find the 'EENS Cost' index. 


\subsection{EENS Determination for Example Case}

A simple 4 bus system is used to test the tool performance. This small system is used because the minimum required load shedding in system contingency cases for the system are known and the result of the tool can be compared to these known values. The 4 bus system is shown in Fig. 5 .

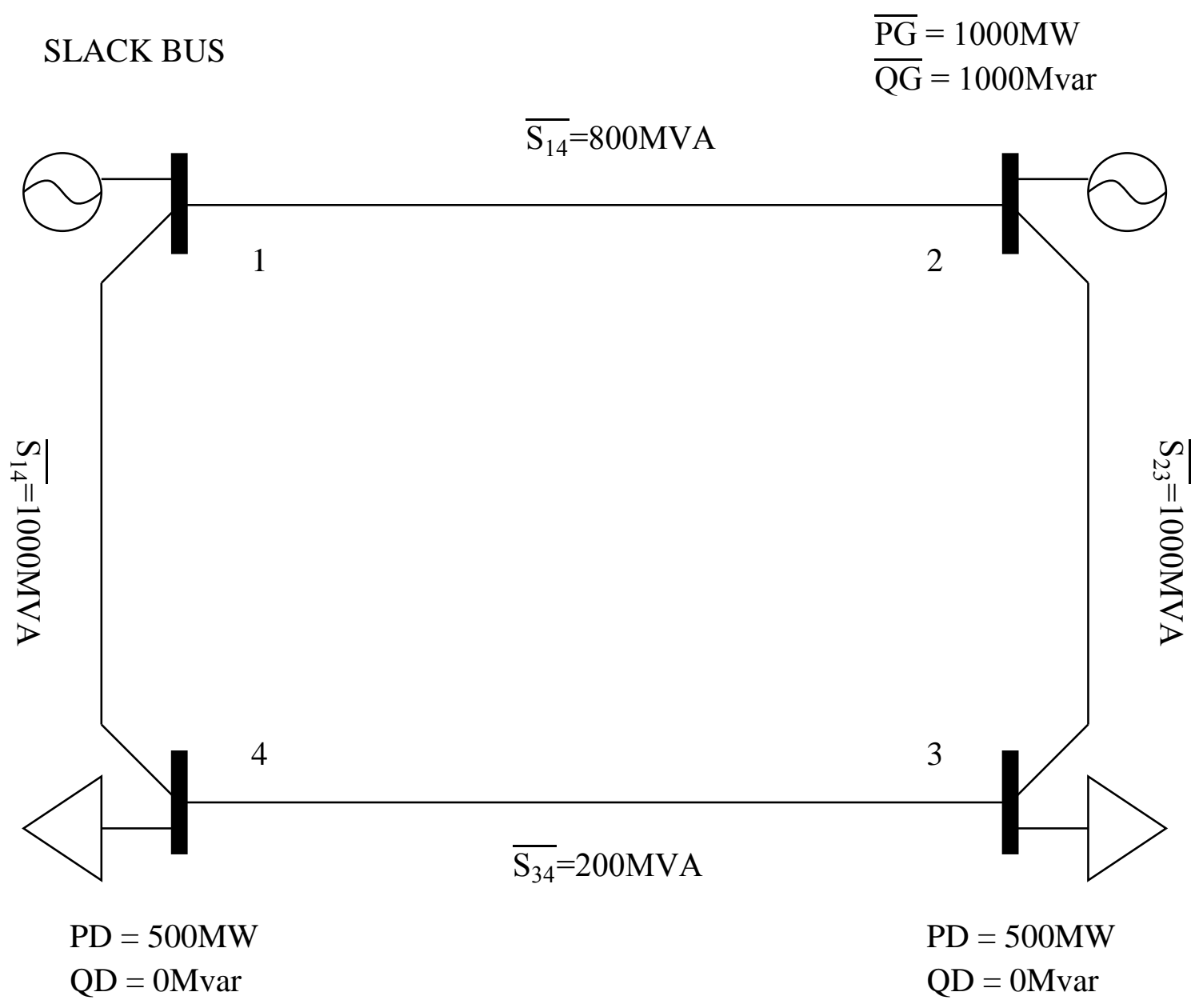

Fig. 5. 4 bus test system. 
In this network, N-1 contingencies of losing line between buses 1-2 or buses 3-4 do not result in load shedding as there is sufficient generating capacity and transmission capacity to supply the loads. When line between buses is 1-4 is lost as an N-1 contingency, the load at bus 4 is only supplied through line 3-4 with a 200 MVA limit. Since the load is 500 MW, the minimum amount of load shed should be $300 \mathrm{MW}$. The same amount should be shed at bus 3 when line between buses 2-3 is lost. The results of solving (7)-(16) determining EENS various N-1 contingencies are shown in Table 1. As it is apparent, the formulation worked as expected whereby no load was shed in the first and fourth contingencies and $300 \mathrm{MW}$ was shed in N-1 contingencies cases 2 and 3 where lines between busses 1-4 and 2-3 were lost respectively.

After analyzing the contingencies of the original system, reinforcements are made to the system to check if the formulation of (7) to (16) works considering these reinforcements. To prevent load shedding when lines between buses 1-4 or 2-3 are lost, one line each with 400 MVA rating were added between bus 1 and 3 and between bus 2 and 4 . The reinforced transmission system is shown in Fig. 6.

In the event of $\mathrm{N}-1$ contingency such that line $2-3$ is lost, addition of line $1-3$ will result in two lines considering line 4-3 with a combined rating of 600 MVA that is sufficient to feed load of $500 \mathrm{MW}$ at bus 3 and avoid load shedding. The same goes for line between buses 2-4. Hence, in this reinforced transmission system, no load shedding should result in any of the 4 contingency cases. The results of the formulation (7)-(16) for N-1 contingencies on the modified system are shown in Table 2 and no load was shed in any of the contingency cases. 
TABLE 1

Minimum LOAD SHEDDING OPF RESUlTS ON 4 Bus SysteM

\begin{tabular}{|c|c|c|c|c|c|c|}
\hline $\begin{array}{c}\text { Contingency } \\
\text { Case }\end{array}$ & Connection & Real Load & Reactive & Shed \\
$(\mathrm{MW})$ & $\begin{array}{c}\text { Load Shed } \\
\text { (Mvar) }\end{array}$ & $\begin{array}{c}\text { Failure Duration for } \\
\text { Each Contingency (hr) }\end{array}$ & $\begin{array}{c}\text { Number of } \\
\text { Failures per } \\
\text { Year }\end{array}$ & $\begin{array}{c}\text { EENS } \\
\text { (c) }\end{array}$ \\
\hline 1 & $1-2$ & 0 & 0 & 12 & 2.2 & 0 \\
\hline 2 & $1-4$ & 300.712 & 0 & 12 & 1.1 & 3969 \\
\hline 3 & $2-3$ & 300.001 & 0 & 12 & 1.1 & 3960 \\
\hline 4 & $3-4$ & 0 & 0 & 12 & 2.2 & 0 \\
\hline
\end{tabular}


SLACK BUS

$$
\begin{aligned}
& \overline{\mathrm{PG}}=1000 \mathrm{MW} \\
& \overline{\mathrm{QG}}=1000 \mathrm{Mvar}
\end{aligned}
$$

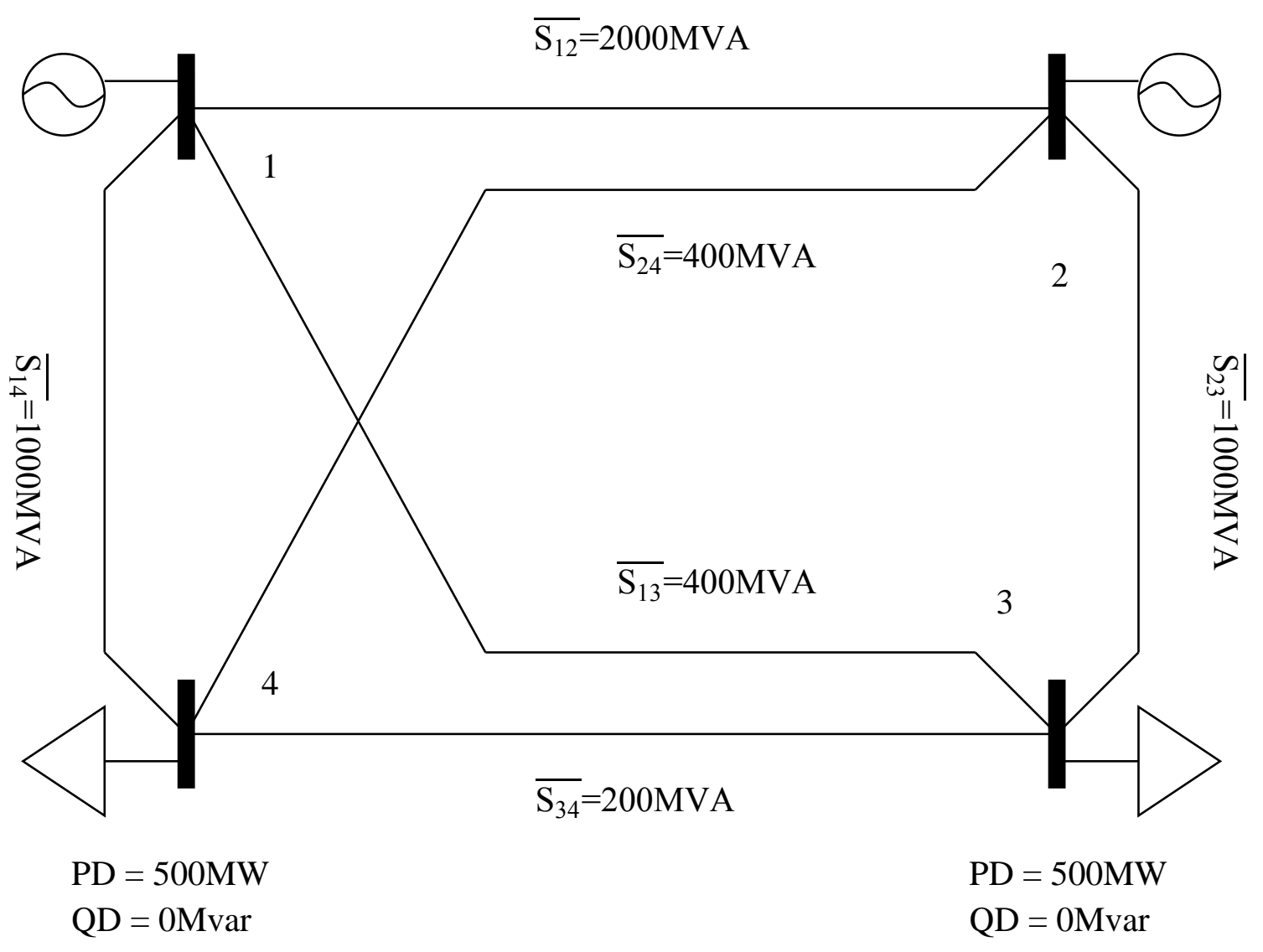

Fig. 6. Modified 4 bus system. 
TABLE 2

Minimum LoAd SHEDDING OPF REsults ON ModifiEd 4 Bus System

\begin{tabular}{|c|c|c|c|c|c|c|}
\hline $\begin{array}{c}\text { Contingency } \\
\text { Case }\end{array}$ & $\begin{array}{l}\text { Connection } \\
\text { Removed }\end{array}$ & $\begin{array}{c}\text { Real Load } \\
\text { Shed } \\
\text { (MW) }\end{array}$ & $\begin{array}{c}\text { Reactive } \\
\text { Load Shed } \\
\text { (Mvar) }\end{array}$ & $\begin{array}{l}\text { Failure Duration for } \\
\text { Each Contingency } \\
\text { (hr) }\end{array}$ & $\begin{array}{c}\text { Number of } \\
\text { Failures per } \\
\text { Year }\end{array}$ & $\begin{array}{c}\text { EENS } \\
\text { (c) }\end{array}$ \\
\hline 1 & $1-2$ & 0 & 0 & 12 & 2.2 & 0 \\
\hline 2 & $1-4$ & 0 & 0 & 12 & 1.1 & 0 \\
\hline 3 & $2-3$ & 0 & 0 & 12 & 1.1 & 0 \\
\hline 4 & $3-4$ & 0 & 0 & 12 & 2.2 & 0 \\
\hline \multicolumn{6}{|c|}{ Total EENS } & 0 \\
\hline
\end{tabular}




\section{Chapter 3 - Probabilistic Routines to Determine Optimal System Upgrade Suggestions}

\subsection{Background}

Due to the complexity of a transmission system network, manual determination of system reinforcements to minimize EENS and comparing its cost of upgrade is a challenging and complex task. Accordingly, probabilistic routines are proposed and developed which suggests system reinforcements. The routines provide upgrade suggestion for system connections:

- $\quad$ Routine 1: $\quad$ Upgrade lines and / or transformer

- $\quad$ Routine 2: $\quad$ Upgrade only lines

- $\quad$ Routine 3: $\quad$ Upgrade only transformers

The routines as indicated either work on both lines and transformers or only one of them. The output of these routines provides suggestions on which system connection MVA ratings to increase to improve the reliability of the system.

\subsection{Routine Procedure}

In many contingency cases for a transmission system, load shedding is required due to the limited capacity of branch and transformers in terms of the amount of electric power that can 
flow through these connections. The output of this routine provides suggestions on which system connection MVA ratings to increase to improve the reliability of the system. There are various possible contingencies in a system for which load shedding may be required. For each of these contingencies, increasing the limits of a particular set of connections may alleviate load shedding. The routine is developed so that connections for which their upgrade would improve the resilience of the system to relatively higher number of contingency scenarios are provided as suggestions. This is done by running an optimal power formulation on each contingency which determines what connections to upgrade to prevent load shedding in that case. Once this has been performed on all the cases, the total MVA limit increase of each connection is obtained by adding its MVA increase for all the contingency cases and the top suggestions are obtained from the connections with the highest total MVA increases. This is explained using a sample system below.

\section{$\underline{\text { Sample System }}$}

To show how the routine provides upgrade suggestions, the system shown in Fig. 7 is used. The load levels, generation capacity and connection flow limits of the system are shown in the figure. The connection impedances as well as the frequency and mean duration of their outage for a projected year are shown in Table 3 . 
TABLE 3

DATA FOR THE 7 BUS SYSTEM

\begin{tabular}{|c|c|c|c|c|c|c|c|}
\hline $\begin{array}{c}\text { Line or } \\
\text { Transformer }\end{array}$ & $\begin{array}{l}\text { From } \\
\text { Bus }\end{array}$ & $\begin{array}{l}\text { To } \\
\text { Bus }\end{array}$ & $\begin{array}{l}\text { Failure Duration for } \\
\text { Each Contingency } \\
\text { (hr) }\end{array}$ & $\begin{array}{c}\text { Number of } \\
\text { Failures per } \\
\text { Year }\end{array}$ & $\mathrm{R}(\mathrm{pu})$ & $\mathrm{X}(\mathrm{pu})$ & $\begin{array}{c}\text { Half Line } \\
\text { Charging } \\
\text { (pu) }\end{array}$ \\
\hline Transformer & 1 & 2 & 0.2 & 424 & 0.0009 & 0.0002 & 0 \\
\hline Transformer & 1 & 3 & 0.2 & 424 & 0.0001 & 0.0006 & 0 \\
\hline Transformer & 1 & 4 & 0.2 & 424 & 0.0009 & 0.0002 & 0 \\
\hline Transformer & 3 & 6 & 0.2 & 255 & 0.0002 & 0.0005 & 0 \\
\hline Line & 2 & 5 & 1 & 16 & 0.0001 & 0.0005 & 0.0007 \\
\hline Line & 4 & 7 & 1 & 16 & 0.0001 & 0.0005 & 0.0007 \\
\hline Line & 5 & 6 & 0.5 & 16 & 0.0002 & 0.0003 & 0.0001 \\
\hline Line & 6 & 7 & 0.5 & 16 & 0.0002 & 0.0003 & 0.0001 \\
\hline
\end{tabular}




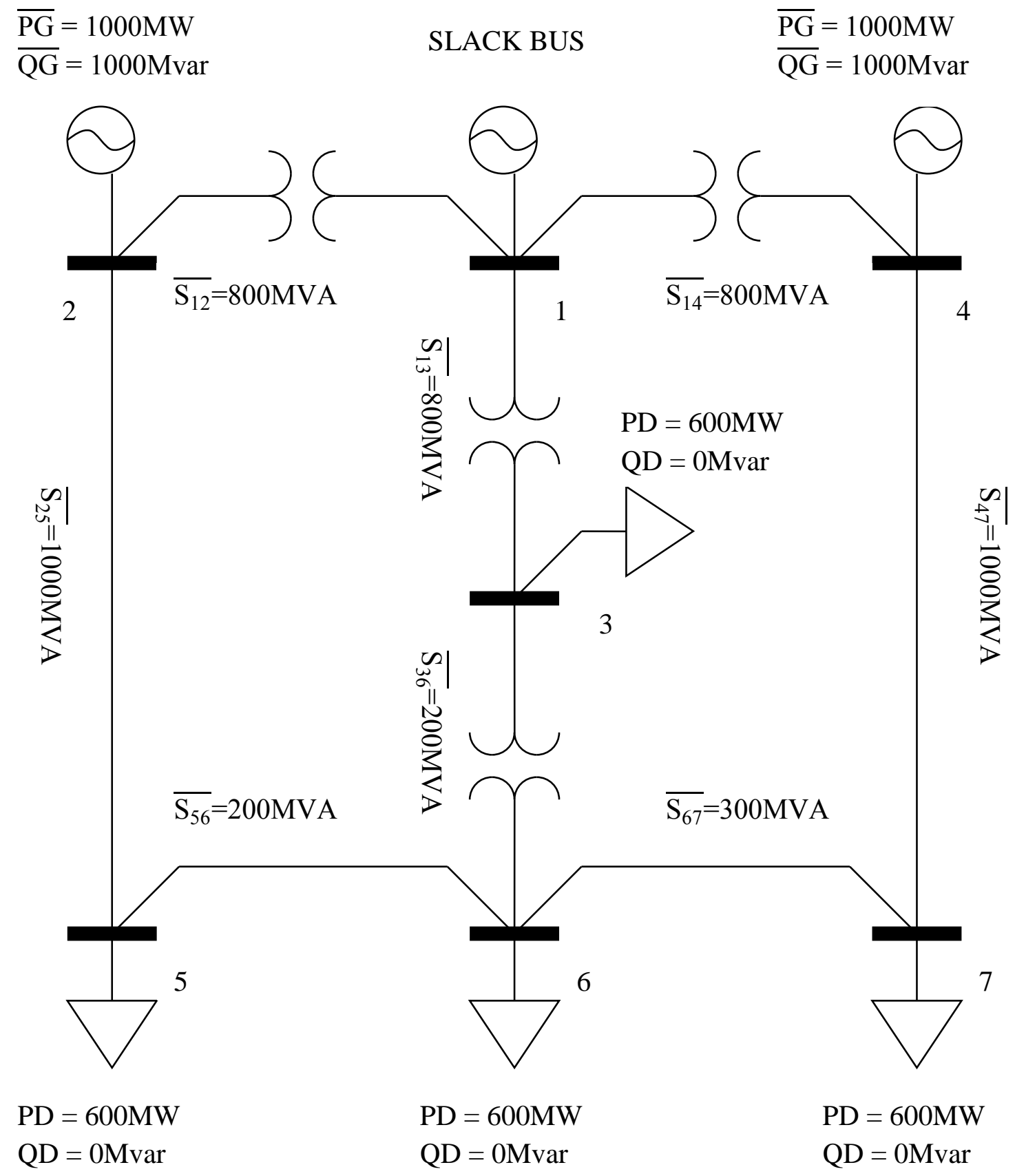

Fig. 7.7 bus test system. 
One of the contingencies of this 7 bus system is outage of connection 6-7. When this outage occurs, due to the limit of 200MVA at connections 3-6 and 5-6 and a load of 600MW at bus 6, a load shedding of at least 200MW is required at bus 6 . One method of modifying the system to prevent load shedding in such a contingency is to increase the MVA rating of connection 5-6 from 200MVA to 400MVA, since connection 2-5 has a rating of 1000MVA and an extra 400MVA can be supplied from bus 5 to 6 after supplying the 600MW load at bus 5 . Another approach is upgrading connections 1-3 and 3-6 to 1000MVA and 400MVA respectively. Although both of these modifications would prevent load shedding when connection 6-7 is removed, one requires a total MVA rating increase of 200MVA while the other requires an MVA increase of 400MVA. Increasing the rating of connections 1-2, 1-4, 2-5 and 4-7 would not prevent load shedding. Various system modifications and their corresponding total MVA upgrade and the required load shedding in the 6-7 connection outage contingency is shown in Table 4. 
TABLE 4

SYSTEM MODIFICATION OPTIONS

\begin{tabular}{|c|c|c|}
\hline System Modification & $\begin{array}{l}\text { Required Real } \\
\text { Load Shedding } \\
\text { When } \\
\text { Connection 6-7 is } \\
\text { Removed (MW) }\end{array}$ & $\begin{array}{c}\text { Total MVA Rating } \\
\text { Upgrade }\end{array}$ \\
\hline $\begin{array}{c}\text { Increase 5-6 rating by } \\
\text { 200MVA }\end{array}$ & 0 & 200 \\
\hline $\begin{array}{l}\text { Increase } 1-3 \text { and 3-6 } \\
\text { rating by } 200 \mathrm{MVA}\end{array}$ & 0 & 400 \\
\hline $\begin{array}{c}\text { Increase all ratings by } \\
\text { 200MVA }\end{array}$ & 0 & 1600 \\
\hline $\begin{array}{l}\text { Increase } 1-2 \text { and } 1-4 \\
\text { rating by } 200 \mathrm{MVA}\end{array}$ & 200 & 400 \\
\hline
\end{tabular}


As it is apparent from Table 4, the best system modification to prevent load shedding when connection 6-7 is removed is to upgrade connection 5-6 by 200MVA. That is because this modification would prevent load shedding and would require the lowest amount of MVA rating increase. An optimal power formulation is developed to find the minimum required MVA increase for the system connections to prevent load shedding in a contingency case. This formulation is explained in the next section. To provide the top upgrade suggestions for the system under study, the OPF is used for all system contingencies. The result of this is shown in Table 5 for the sample system. 
TABLE 5

Results Used to Provide UpgRade SugGestions

\begin{tabular}{|c|c|c|c|c|c|c|c|c|c|}
\hline \multirow{2}{*}{$\begin{array}{l}\text { Connection } \\
\text { Removed }\end{array}$} & \multirow{2}{*}{$\begin{array}{l}\text { Frequency of } \\
\text { Contingency }\end{array}$} & \multicolumn{8}{|c|}{ connection } \\
\hline & & $2-5$ & 4-7 & $5-6$ & $6-7$ & $1-2$ & $1-3$ & $1-4$ & $3-6$ \\
\hline $2-5$ & 0.2 & 0 & 200 & 400 & 300 & 0 & 400 & 0 & 400 \\
\hline $4-7$ & 0.2 & 200 & 0 & 400 & 300 & 0 & 400 & 0 & 400 \\
\hline $5-6$ & 0.2 & 0 & 0 & 0 & 100 & 0 & 0 & 0 & 0 \\
\hline $6-7$ & 0.2 & 0 & 0 & 200 & 0 & 0 & 0 & 0 & 0 \\
\hline $1-2$ & 1 & 0 & 0 & 0 & 0 & 0 & 0 & 0 & 0 \\
\hline $1-3$ & 1 & 200 & 200 & 400 & 300 & 0 & 0 & 0 & 400 \\
\hline $1-4$ & 0.5 & 0 & 0 & 0 & 0 & 0 & 0 & 0 & 0 \\
\hline $3-6$ & 0.5 & 0 & 0 & 50 & 50 & 0 & 0 & 0 & 0 \\
\hline $\begin{array}{r}\text { Sum of Upgr } \\
\text { Contingencie } \\
\text { Cont }\end{array}$ & $\begin{array}{l}\text { alues of all } \\
\text { equency of }\end{array}$ & 240 & 240 & 625 & 465 & 0 & 160 & 0 & 560 \\
\hline
\end{tabular}


For each contingency, the OPF obtains the minimum connection MVA upgrade to prevent load shedding, which may include upgrading more than one connection. Once the connection upgrades for all system contingencies are obtained, the connections most often upgraded will be the top suggestions for system modifications. The last column of Table 5 shows the sum of MVA limit increase of each connection for all contingencies. For the 7 bus system under study, the top suggestions are 5-6 and 3-6. It should also be noted that the MVA increase numbers of each row are multiplied by the frequency of the corresponding contingency. This is done because upgrading some connections may alleviate load shedding for relatively unlikely contingencies. Multiplication by the frequency of the contingency will ensure the top suggestions are the ones which ensure ideal operation of the system for contingencies with higher probability of occurring. The next section gives the formulation of the OPF used for the upgrade suggestion routine.

\subsection{Optimal Power Flow Used in Branch/Transformer Upgrade Suggestion Routine}

\section{$\underline{\text { Decision and Dependent Variables }}$}

Since there is no load shedding in this OPF formulation, there is no load shedding decision variables (PS and QS). The decision variables for the formulation include the power generation (PG and QG) and a new variable $\mathrm{SU}_{\mathrm{ik}}$. The $\mathrm{SU}_{\mathrm{ik}}$ variable is additional MVA flow limit for the system connections where the $U$ stands for upgrade. That is, the formulation attempts to find a power flow solution without load shedding and using the generation limits and additional 
connection flow limits as decision variables.

The dependent variables used for the OPF are the bus voltage magnitudes $\left|V_{i}\right|$ and angles $\delta_{i}$ for all $\mathrm{i}$ buses, the calculated power at each bus (P and Q) and MVA flow on transmission lines $\left(\mathrm{S}_{\mathrm{ik}}\right)$. The Load (PD and QD) and system admittance matrix Y(c) are constants.

\section{$\underline{\text { Constraints }}$}

Equality constraints from bus-wise power balance equations are given in (17), (18) and (19). The $\mathrm{SU}_{\mathrm{ik}}$ variable is used in the non-equality constraint equations.

$$
\begin{gathered}
\mathrm{PG}_{\mathrm{i}}-\mathrm{PD}_{\mathrm{i}}=\mathrm{P}_{\mathrm{i}} \\
\mathrm{P}_{\mathrm{i}}=\sum_{\mathrm{k}=1}^{\mathrm{N}}\left|\mathrm{Y}_{\mathrm{ik}} \cdot \mathrm{V}_{\mathrm{i}} \cdot \mathrm{V}_{\mathrm{k}}\right| \cdot \cos \left(\delta_{\mathrm{i}}-\delta_{\mathrm{k}}-\theta_{\mathrm{ik}}\right) \\
\mathrm{QG}_{\mathrm{i}}-\mathrm{QD}_{\mathrm{i}}=\mathrm{Q}_{\mathrm{i}} \\
\mathrm{Q}_{\mathrm{i}}=\sum_{\mathrm{k}=1}^{\mathrm{N}}\left|\mathrm{Y}_{\mathrm{ik}} \cdot \mathrm{V}_{\mathrm{i}} \cdot \mathrm{V}_{\mathrm{k}}\right| \cdot \sin \left(\delta_{\mathrm{i}}-\delta_{\mathrm{k}}-\theta_{\mathrm{ik}}\right) \\
\mathrm{S}_{\mathrm{ik}}=\mathrm{V}_{\mathrm{i}} \cdot\left[\left(\mathrm{V}_{\mathrm{i}}-\mathrm{V}_{\mathrm{k}}\right) \cdot\left(\mathrm{y}_{\mathrm{ik}}\right)\right]^{*}
\end{gathered}
$$

The non-equality constraints for the formulation include the bus voltage magnitudes and the generated real and reactive power at each bus. Also, the additional flow limit $\mathrm{SU}_{\mathrm{ik}}$ must be greater than zero. The calculated connection flow for each connection must be less than the original system limit $\overline{\mathrm{S}_{\mathrm{ik}}}$ plus the additional upgrade $\mathrm{SU}_{\mathrm{ik}}$. These constraints are given in (20) to 


$$
\begin{gathered}
|\underline{V}|<\left|\mathrm{V}_{\mathrm{i}}\right|<|\overline{\mathrm{V}}| \\
\underline{P G}<P G<\overline{\mathrm{PG}} \\
\underline{Q G}<Q G<\overline{\mathrm{QG}} \\
\mathrm{SU}_{\mathrm{ik}}>0 \\
\left|\mathrm{~S}_{\mathrm{ik}}\right|=\left|\mathrm{V}_{\mathrm{i}} \cdot\left[\left(\mathrm{V}_{\mathrm{i}}-\mathrm{V}_{\mathrm{k}}\right) \cdot\left(\mathrm{y}_{\mathrm{ik}}\right)\right]^{*}\right|<\overline{\mathrm{S}_{\mathrm{ik}}}+\mathrm{SU}_{\mathrm{ik}}
\end{gathered}
$$

\section{$\underline{\text { Objective Function }}$}

The objective function is the sum of all the $\mathrm{SU}_{\mathrm{ik}}$ variables multiplied by the upgrade difficulty scale constant. This is given in (25), where NC denotes number of lines and / or transformers and $\mathrm{c}$ is the contingency being analyzed.

$$
\text { Minimize: Additional Flow Capacity (c) }=\sum_{\mathrm{ik}=1}^{\mathrm{NC}}\left[\mathrm{SU}_{\mathrm{ik}} * \mathrm{UDS}_{\mathrm{ik}}\right]
$$

The UDS ${ }_{\text {ik }}$ parameter is used due to the varying difficulty to upgrade lines and/or transformers. This may be due to factors such as cost, environmental concerns, right way issues, etc. By using this parameter, the optimization algorithm will try to find a solution where connections with less upgrade difficulty are upgraded to eliminate load shedding. 


\section{Chapter 4 - Results on Sample System}

The reliability tool was tested on a 7-bus and the IEEE 118 bus system. The calculated reliability index for the original system as well as for system modifications is shown for comparisons. An actual North American system was also used to test the proposed method and is reported.

\subsection{Data Used for Upgrade Cost Estimates}

To estimate the costs of system upgrades, a 2012 report submitted by the Black \& Veatch Corporation to the Western Electricity Coordinating Council titled 'Capital Costs for Transmission and Substation' was used [7]. Using information such as voltage ratings, transmission line lengths, etc the cost of upgrading a transformer or transmission line could be obtained from the report. The report contained estimated costs for transmission lines and substation components for a selected range of voltage class. The voltage classes are shown in Table 6. 
TABLE 6

TRANSMISSION AND SUBSTATION FACILITIES INCLUDED IN THE STUDY

\begin{tabular}{|c|c|}
\hline TRANSMISSION LINE VOLTAGE CLASSES & SUBSTATION TYPES \\
\hline $230 \mathrm{kV}$ Single Circuit & $230 \mathrm{kV}$ \\
\hline $230 \mathrm{kV}$ Double Circuit & $345 \mathrm{kV}$ \\
\hline $345 \mathrm{kV}$ Single Circuit & $500 \mathrm{kV}(\mathrm{ac})$ \\
\hline $345 \mathrm{kV}$ Double Circuit & $500 \mathrm{kV}(\mathrm{dc})$ \\
\hline $500 \mathrm{kV}$ Single Circuit & \\
\hline $500 \mathrm{kV}$ Double Circuit & \\
\hline $500 \mathrm{kV}$ HVDC Bi-pole & \\
\hline
\end{tabular}

Wherever a component was chosen for upgrade where the voltage class was not included in table a, the closest voltage class was chosen. The report used a "bottom-up" approach for providing estimate costs. That is, by detailing the component and land cost and then adjusting them to take into consideration potential cost variations such as location and terrain.

The data used to obtain transmission line installation costs are shown in Table 7. The table contains the base cost per mile for the transmission line as well as multipliers depending on various factors such as conductor type, structure, length, etc. Also, similar data are given for substation and substation component installation costs in Table 8. 
TABLE 7

TRANSMISSION CAPITAL COST SUMMERY

\begin{tabular}{|c|c|c|c|c|c|c|c|}
\hline EQUIPMENT & $\begin{array}{l}230 \mathrm{KV} \\
\text { SINGLE } \\
\text { CIRCUIT }\end{array}$ & $\begin{array}{l}230 \mathrm{KV} \\
\text { DOUBLE } \\
\text { CIRCUIT }\end{array}$ & $\begin{array}{l}345 \mathrm{KV} \\
\text { SINGLE } \\
\text { CIRCUIT }\end{array}$ & $\begin{array}{c}345 \mathrm{KV} \\
\text { DOUBLE } \\
\text { CIRCUIT }\end{array}$ & $\begin{array}{l}500 \mathrm{KV} \\
\text { SINGLE } \\
\text { CIRCUIT }\end{array}$ & $\begin{array}{c}500 \mathrm{KV} \\
\text { DOUBLE } \\
\text { CIRCUIT }\end{array}$ & $\begin{array}{c}500 \mathrm{KV} \\
\text { HVDC BI- } \\
\text { POLE }\end{array}$ \\
\hline Base Cost & $\$ 927,000$ & $\$ 1,484,000$ & $\$ 1,298,000$ & $\$ 2,077,000$ & $\$ 1,854,000$ & $\$ 2,967,000$ & $\$ 1,484,000$ \\
\hline \multicolumn{8}{|c|}{ Multipliers } \\
\hline \multicolumn{8}{|c|}{ Conductor } \\
\hline ACSR & 1.00 & 1.00 & 1.00 & 1.00 & 1.00 & 1.00 & 1.00 \\
\hline ACSS & 1.08 & 1.08 & 1.08 & 1.08 & 1.08 & 1.08 & 1.08 \\
\hline HTLS & 3.60 & 3.60 & 3.60 & 3.60 & 3.60 & 3.60 & 3.60 \\
\hline \multicolumn{8}{|c|}{ Structure } \\
\hline Lattice & 0.90 & 0.90 & 1.00 & 1.00 & 1.00 & 1.00 & 1.00 \\
\hline Tubular Steel & 1.00 & 1.00 & 1.30 & 1.30 & 1.50 & 1.50 & 1.50 \\
\hline \multicolumn{8}{|c|}{ Length } \\
\hline$>10$ miles & 1.00 & 1.00 & 1.00 & 1.00 & 1.00 & 1.00 & 1.00 \\
\hline 3-10 miles & 1.20 & 1.20 & 1.20 & 1.20 & 1.20 & 1.20 & 1.20 \\
\hline$<3$ miles & 1.50 & 1.50 & 1.50 & 1.50 & 1.50 & 1.50 & 1.50 \\
\hline \multicolumn{8}{|c|}{ Age } \\
\hline New & 1.00 & 1.00 & 1.00 & 1.00 & 1.00 & 1.00 & 1.00 \\
\hline Re-conductor & 0.35 & 0.45 & 0.45 & 0.55 & 0.55 & 0.65 & 0.55 \\
\hline \multicolumn{8}{|c|}{ Terrain } \\
\hline Desert & 1.05 & 1.05 & 1.05 & 1.05 & 1.05 & 1.05 & 1.05 \\
\hline Scrub / Flat & 1.00 & 1.00 & 1.00 & 1.00 & 1.00 & 1.00 & 1.00 \\
\hline Farmland & 1.00 & 1.00 & 1.00 & 1.00 & 1.00 & 1.00 & 1.00 \\
\hline Forested & 2.25 & 2.25 & 2.25 & 2.25 & 2.25 & 2.25 & 2.25 \\
\hline $\begin{array}{l}\text { Rolling Hill } \\
\text { (2-8\% slope) }\end{array}$ & 1.40 & 1.40 & 1.40 & 1.40 & 1.40 & 1.40 & 1.40 \\
\hline $\begin{array}{l}\text { Mountain } \\
\text { (>8\% slope) }\end{array}$ & 1.75 & 1.75 & 1.75 & 1.75 & 1.75 & 1.75 & 1.75 \\
\hline Wetland & 1.20 & 1.20 & 1.20 & 1.20 & 1.20 & 1.20 & 1.20 \\
\hline Suburban & 1.27 & 1.27 & 1.27 & 1.27 & 1.27 & 1.27 & 1.27 \\
\hline Urban & 1.59 & 1.59 & 1.59 & 1.59 & 1.59 & 1.59 & 1.59 \\
\hline
\end{tabular}


TABLE 8

SubStation CAPITAL Cost Summery

\begin{tabular}{|c|c|c|c|}
\hline EQUIPMENT & $\begin{array}{c}230 \mathrm{KV} \\
\text { SUBSTATION }\end{array}$ & $\begin{array}{c}345 \mathrm{KV} \\
\text { SUBSTATION }\end{array}$ & $\begin{array}{c}500 \mathrm{KV} \\
\text { SUBSTATION }\end{array}$ \\
\hline Base Cost (New Substation) & $\$ 1,648,000$ & $\$ 2,060,000$ & $\$ 2,472,000$ \\
\hline Cost Per Line/XFMR Position & $\$ 1,442,000$ & $\$ 2,163,000$ & $\$ 2,884,000$ \\
\hline Ring Bus Multiplier & 1 & 1 & 1 \\
\hline Breaker and a Half Multiplier & 1.5 & 1.5 & 1.5 \\
\hline $500 \mathrm{kV}$ HVDC Converter Station & - & - & $\$ 445,000,000$ \\
\hline Shunt Reactor (\$/MVAR) & $\$ 20,000$ & $\$ 20,000$ & $\$ 20,000$ \\
\hline Series Capacitor (\$/MVAR) & $\$ 30,000$ & $\$ 10,000$ & $\$ 10,000$ \\
\hline SVC Cost (\$/MVAR) & $\$ 85,000$ & $\$ 85,000$ & $\$ 85,000$ \\
\hline \multicolumn{4}{|l|}{ Transformer Cost (\$/MVA) } \\
\hline $115 / 230 \mathrm{kV}$ XFMR & $\$ 7,000$ & - & - \\
\hline $115 / 345 \mathrm{kV}$ XFMR & - & $\$ 10,000$ & - \\
\hline $115 / 500 \mathrm{kV}$ XFMR & - & - & $\$ 10,000$ \\
\hline $138 / 230 \mathrm{kV}$ XFMR & $\$ 7,000$ & - & - \\
\hline $138 / 345 \mathrm{kV}$ XFMR & - & $\$ 10,000$ & - \\
\hline $138 / 500 \mathrm{kV}$ XFMR & - & - & $\$ 10,000$ \\
\hline $230 / 345 \mathrm{kV}$ XFMR & & $\$ 10,000$ & - \\
\hline $230 / 500 \mathrm{kV}$ XFMR & $\$ 11,000$ & - & $\$ 11,000$ \\
\hline $345 / 500 \mathrm{kV}$ XFMR & - & $\$ 13,000$ & $\$ 13,000$ \\
\hline
\end{tabular}




\subsection{7-Bus Case}

The 7 bus system data were given in Table 3 and Fig. 8. The data of failure frequency and duration is taken from [8] and [9]. The EENS values for the original and variations of the system were obtained to check the performance of the implemented tool in MATLAB, where for example decreases in load levels should result in decreased EENS. This is shown in Table 9. 
TABLE 9

‘EENS COST’ RESULTS FOR ORIGINAL AND VARIATIONS OF SYSTEM UNDER STUDY

\begin{tabular}{|c|c|c|c|c|}
\hline $\begin{array}{c}\text { System Load } \\
\text { and }\end{array}$ & Real EENS & Reactive EENS & Total EENS & Change in EENS \\
Transmission Capacity & Cost & Cost \\
\hline Original Load & 90940 & 0 & 363.8 & - \\
\hline Load (-5\%) & 82002 & 0 & 328 & 35.8 \\
\hline Load (+5\%) & 101318 & 0 & 405.3 & -41.5 \\
\hline Transmission Capacity & 86385 & 0 & 345.6 & 18.2 \\
$(+5 \%)$ & 96775 & 0 & 387.1 & -23.2 \\
\hline Transmission Capacity & & & & \\
\hline
\end{tabular}


The top suggestions from the routines were used to modify the system and to compare the yearly cost of these reinforced systems with the original one. To compare the systems, the cost of system reinforcement had to be determined using the system modification cost tables. To determine the upgrade costs, the base voltage of the buses and the length of branches must also be known. The values selected for these parameters in the 7 bus system are shown in Tables 10 and 11. Using the routine suggestions, the system was reinforced first using the top suggestion and then using the top two suggestions. These suggestions and the amount they were upgraded by are shown in Tables 12 and 13 .

Using the available information, the cost of each upgrade may be determined. For example, the top suggestion for upgrade using routine 1 is increase of connection 5-6 rating by 400MVA. This is a branch connection and its cost can be determined using Table 7. To obtain the cost, the base voltage, circuit type, conductor type, structure, length, age and type of terrain must be selected. Choosing a base voltage of $500 \mathrm{kV}$, a single circuit, ACSR conductor, lattice structure, length of 7 miles, new conductor and flat terrain the cost of upgrading this unit is shown in (26).

$$
\text { Cost of Upgrade } \cong \$ 1.9 \mathrm{~m} * 1 * 1 * 7 * 1.2 * 1=\$ 15.96 \mathrm{~m} \cong \$ 16 \mathrm{~m}
$$

For the cost of transformer upgrades, Table 8 must be used. The information needed in this case is the rated voltage of transformer sides and the amount of MVA increase. To find the total cost, the base cost of upgrade must first be determined. This base cost is the cost of adding a substation and the cost per added line/XFMR position. They are determined by the rated voltage of the transformer. For example, the top suggestion for upgrade from routine 3 is the 1-3 
transformer connection. This connection has a voltage rating of $500 \mathrm{kV}$ and using this value the base cost for adding another transformer to increase the MVA rating of the connection is shown in (27).

$$
\text { Base cost }=\text { Substation Cost }+ \text { Cost of One Line } \cong \$ 2.5 \mathrm{~m}+\$ 2.9 \mathrm{~m}=\$ 5.4 \mathrm{~m}
$$

Once the base cost is determined, the additional cost depends on the amount of additional MVA rating. In this case the additional MVA is 200MVA and the cost per MVA for a 345/500 kV transformer is $\$ 13000$ from the table. Hence, the cost for amount of additional MVA for upgrading this connection is given in (28).

$$
\text { Cost for additional MVA }=200 \mathrm{MVA} * \frac{\$ 13000}{\mathrm{MVA}}=\$ 2.6 \mathrm{~m}
$$

The total cost is then given by (29).

$$
\text { Total cost }=\$ 5.4 \mathrm{~m}+\$ 2.6 \mathrm{~m}=\$ 8 \mathrm{~m}
$$

The cost for all system modifications were determined using this approach. The results for yearly cost of the original system and re-enforced systems are shown in Tables 14 and 15. 
TABLE 10

7 Bus Base Voltages

\begin{tabular}{|c|c|}
\hline Bus & Voltage $(\mathrm{kV})$ \\
\hline 1 & 230 \\
\hline 2 & 500 \\
\hline 3 & 345 \\
\hline 4 & 500 \\
\hline 5 & 500 \\
\hline 6 & 500 \\
\hline 7 & 500 \\
\hline
\end{tabular}

TABLE 11

7 BuS BRANCH CONNECTION LENGTHS

\begin{tabular}{|c|c|}
\hline Branch & Length (miles) \\
\hline $2-5$ & 8 \\
\hline $4-7$ & 4 \\
\hline $5-6$ & 7 \\
\hline $6-7$ & 5 \\
\hline
\end{tabular}

TABLE 12

TOP SugGESTION FOR UPGRADE FROM EACH ROUTINE

\begin{tabular}{|c|c|c|}
\hline Routine & Element upgraded & MVA rating increase \\
\hline 1 & $5-6$ & 400 \\
\hline 2 & $5-6$ & 200 \\
\hline 3 & $1-3$ & 200 \\
\hline
\end{tabular}

TABLE 13

ToP Two SugGESTION FOR UPGRADE FROM EACH ROUTINE

\begin{tabular}{|c|c|c|c|c|}
\hline Routine & $\begin{array}{c}\text { Element } \\
\text { upgraded \# 1 }\end{array}$ & $\begin{array}{c}\text { MVA rating } \\
\text { increase }\end{array}$ & $\begin{array}{c}\text { Element } \\
\text { upgraded \# 2 }\end{array}$ & $\begin{array}{c}\text { MVA rating } \\
\text { increase }\end{array}$ \\
\hline 1 & $5-6$ & 400 & $3-6$ & 400 \\
\hline 2 & $5-6$ & 200 & $6-7$ & 100 \\
\hline 3 & $3-6$ & 200 & $1-3$ & 200 \\
\hline
\end{tabular}


TABLE 14

RELIABILITy INDEX VALUES OF RE-ENFORCED 7 Bus System USING ToP ROUTINE SugGeSTIONS

\begin{tabular}{|c|c|c|c|c|c|c|}
\hline System & $\begin{array}{c}\text { ELNS } \\
\text { Index } \\
\text { Real Load } \\
(\mathrm{MW})\end{array}$ & $\begin{array}{c}\text { ELNS Index } \\
\text { Reactive } \\
\text { Load (Mvar) }\end{array}$ & $\begin{array}{l}\text { EENS Cost } \\
\text { (million \$) }\end{array}$ & $\begin{array}{c}\text { Cost of } \\
\text { System } \\
\text { Modification } \\
\text { (million \$) }\end{array}$ & $\begin{array}{l}\text { Total Cost } \\
\text { (million \$) }\end{array}$ & $\begin{array}{c}\text { Benefit from } \\
\text { Upgrade }\end{array}$ \\
\hline $\begin{array}{l}\text { Original } \\
\text { System }\end{array}$ & 2600 & 0 & 363.4 & 0 & 363.4 & - \\
\hline $\begin{array}{c}\text { Upgrade Using } \\
\text { Routine } 1\end{array}$ & 1905 & 0 & 256.2 & 16 & 272.2 & 91.2 \\
\hline $\begin{array}{c}\text { Upgrade } \\
\text { Using } \\
\text { Routine } 2\end{array}$ & 1905 & 0 & 256.2 & 16 & 272.2 & 91.2 \\
\hline $\begin{array}{c}\text { Upgrade } \\
\text { Using } \\
\text { Routine } 3\end{array}$ & 2600 & 0 & 363.4 & 8 & 379.4 & -8 \\
\hline
\end{tabular}


TABLE 15

Reliability Index VALues of Re-ENFORCED 7 Bus System Using ToP Two Routine

SUGGESTIONS

\begin{tabular}{|c|c|c|c|c|c|c|}
\hline System & $\begin{array}{c}\text { ELNS } \\
\text { Index } \\
\text { Real Load } \\
(\mathrm{MW})\end{array}$ & \begin{tabular}{|c|} 
ELNS Index \\
Reactive \\
Load (Mvar)
\end{tabular} & $\begin{array}{l}\text { EENS Cost } \\
\text { (million } \$ \text { ) }\end{array}$ & $\begin{array}{c}\text { Cost of } \\
\text { System } \\
\text { Modification } \\
\text { (million \$) }\end{array}$ & $\begin{array}{l}\text { Total Cost } \\
\text { (million \$) }\end{array}$ & $\begin{array}{c}\text { Benefit from } \\
\text { Upgrade }\end{array}$ \\
\hline $\begin{array}{l}\text { Original } \\
\text { System }\end{array}$ & 2600 & 0 & 363.4 & 0 & 363.4 & - \\
\hline $\begin{array}{c}\text { Upgrade Using } \\
\text { Routine } 1\end{array}$ & 1905 & 0 & 256.2 & 26.6 & 282.8 & 80.6 \\
\hline $\begin{array}{c}\text { Upgrade } \\
\text { Using } \\
\text { Routine } 2\end{array}$ & 1610 & 0 & 212.8 & 27.4 & 240.2 & 123.2 \\
\hline $\begin{array}{c}\text { Upgrade } \\
\text { Using } \\
\text { Routine } 3\end{array}$ & 1900 & 0 & 328.2 & 14.3 & 342.5 & 20.9 \\
\hline
\end{tabular}


By using the formulation (7) to (16), the EENS value for the system was determined to equal: $\$ 363.8$ million, as reported in Table 9. The reliability tool analysis considered the base load and effect of changing load by $\pm 5 \%$ and transmission capacity by $\pm 5 \%$. The results are as expected in all cases.

By using formulation in (17)-(25), the transmission system was reinforced. This optimal reinforcement was completed using Routines 1,2 and 3. Their results were tabulated in Table 10. The results clearly demonstrate that using the proposed formulation of $(17)-(25)$, the best upgrades that are both viable and cost effective are chosen.

\subsection{IEEE 118-Bus System}

The data for the 118-bus system was taken from [10] and is provided in the appendix. Considering various voltage levels, the failure duration and frequency values were taken from [8] and [9]. These data are too voluminous to for presentation here.

To calculate the indices, the system contingencies and their frequency and duration values for a projected year are considered. The indices for the original system as well as variations such as a reduced load system are shown in Table 16. Once again, variations are shown to illustrate the performance of the formulation proposed in (7)-(16). The results in Table 16 demonstrate that reduction of load or increasing capacity of the transmission system results in reduction of EENS. 
TABLE 16

'EENS COST’ RESULTS FOR ORIGINAL AND VARIATIONS OF SYSTEM UNDER STUDY

\begin{tabular}{|c|c|c|c|c|}
\hline $\begin{array}{c}\text { System Load } \\
\text { and } \\
\text { Transmission Capacity }\end{array}$ & $\begin{array}{l}\text { Real EENS } \\
\left(\mathrm{MW}^{*} \mathrm{hr}\right)\end{array}$ & $\begin{array}{c}\text { Reactive EENS } \\
\text { (Mvar*hr) }\end{array}$ & $\begin{array}{l}\text { Total EENS } \\
\text { Cost } \\
\text { (million \$) }\end{array}$ & $\begin{array}{c}\text { Change in EENS } \\
\text { Cost } \\
\text { (million \$) }\end{array}$ \\
\hline Original Load & 38,600 & 1,000 & 158.4 & - \\
\hline Load $(-5 \%)$ & 36,400 & 8,50 & 146.2 & 12.2 \\
\hline Load $(+5 \%)$ & 40,250 & 1,200 & 165.8 & -7.4 \\
\hline $\begin{array}{l}\text { Transmission Capacity } \\
\qquad(+5 \%)\end{array}$ & 35,350 & 8,00 & 144.6 & 13.8 \\
\hline $\begin{array}{c}\text { Transmission Capacity } \\
(-5 \%)\end{array}$ & 40,500 & 1,050 & 166.2 & -7.8 \\
\hline
\end{tabular}


TABLE 17

TOP THREE SUGGeSTION FOR UPGRADE FROM EACH ROUTINE

\begin{tabular}{|c|c|c|c|c|c|c|}
\hline Routine & $\begin{array}{c}\text { Element } \\
\text { upgraded \# } \\
1\end{array}$ & $\begin{array}{c}\text { MVA rating } \\
\text { increase }\end{array}$ & $\begin{array}{c}\text { Element } \\
\text { upgraded \# } \\
2\end{array}$ & $\begin{array}{c}\text { MVA rating } \\
\text { increase }\end{array}$ & $\begin{array}{c}\text { Element } \\
\text { upgraded } \\
\# 3\end{array}$ & $\begin{array}{c}\text { MVA rating } \\
\text { increase }\end{array}$ \\
\hline 1 & $30-38$ & 250 & $70-74$ & 200 & $80-99$ & 200 \\
\hline 2 & $85-89$ & 150 & $30-38$ & 250 & $70-74$ & 200 \\
\hline 3 & $65-66$ & 300 & $30-17$ & 200 & $38-37$ & 250 \\
\hline
\end{tabular}

TABLE 18

RELIABILITY INDEX VALUES OF SYSTEMS

\begin{tabular}{|c|c|c|c|c|c|c|}
\hline System & $\begin{array}{c}\text { ELNS } \\
\text { Index } \\
\text { Real Load } \\
(\mathrm{MW})\end{array}$ & $\begin{array}{c}\text { ELNS Index } \\
\text { Reactive } \\
\text { Load (Mvar) }\end{array}$ & $\begin{array}{l}\text { EENS Cost } \\
\text { (million \$) }\end{array}$ & $\begin{array}{c}\text { Cost of } \\
\text { System } \\
\text { Modification } \\
\text { (million \$) }\end{array}$ & $\begin{array}{l}\text { Total Cost } \\
\text { (million \$) }\end{array}$ & $\begin{array}{c}\text { Benefit from } \\
\text { Upgrade }\end{array}$ \\
\hline $\begin{array}{l}\text { Original } \\
\text { System }\end{array}$ & 3860 & 100 & 158.4 & - & 158.4 & - \\
\hline $\begin{array}{c}\text { Upgrade Using } \\
\text { Routine } 1\end{array}$ & 3590 & 80 & 146.8 & 6 & 152.8 & 5.6 \\
\hline $\begin{array}{c}\text { Upgrade } \\
\text { Using } \\
\text { Routine 2 }\end{array}$ & 3590 & 80 & 146.8 & 6 & 152.8 & 5.6 \\
\hline $\begin{array}{c}\text { Upgrade } \\
\text { Using } \\
\text { Routine } 3\end{array}$ & 3770 & 90 & 154.4 & 9 & 163.4 & -5 \\
\hline
\end{tabular}


The three routines developed to provide upgrade suggestions for lines and/or transformer were used on the 118 bus system Table 18 shows the results. These routines are referred to as routines 1, 2 and 3 respectively. The top three suggestions from each routine shown in Table 17 were used to upgrade the system in each case and the reliability results are shown in this section. These upgrade solutions were compared with original system state.

As evident from Table 18, when the system is reinforced using the suggestions from routine 1 that considers both lines and transformers for upgrades, there is significant reduction in the EENS cost equaling $\$ 11.6$ million. The EENS costs reduce from $\$ 158.4$ million to $\$ 146.8$ million. For the calculated upgrade costs of $\$ 6$ million, it is evident that the upgrade costs are lesser than reduction in EENS costs of $\$ 11.6$ million. Hence upgrades are feasible and would provide a net profit of $\$ 5.6$ million.

In contrast, considering using routine 3, the transformers only option, it is evident that EENS cost reduction is nominal from $\$ 158.4$ million to $\$ 154.4$ million amounting to $\$ 4$ million whereas upgrade costs are $\$ 9$ million. Hence optimal solution using routine 3 , the transformer upgrade option costs a loss of $\$ 5$ million. Hence, this upgrade option is not viable.

Very clearly, the proposed method efficiently finds the best upgrades such that the projected upgrade costs result in a reduction in EENS cost over and above the upgrade costs and hence provide optimal and viable upgrade option. 


\subsection{A North American System Data}

To check practicality of the proposed method, a North American system was considered for transmission system expansion planning. The system has 304 buses, 194 transmission lines and 163 transformers with a total forecasted load of $5754 \mathrm{MW}$. The EENS cost was determined to equal \$182 million per year using formulation (7)-(16). Considering various voltage levels, the failure duration and frequency values were taken from [8] and [9].

Thereafter using the proposed expansion planning tool (17)-(25), routine 1 proposed an expansion plan worth $\$ 60$ million and reduced EENS costs per year by $\$ 26$ million, which may make up for the cost over several years. Comparing these costs and seeing the benefit of these expansion plans, several of them are underway. 


\section{Chapter 5 - Conclusion}

\subsection{Summary of Work Done in the Thesis}

This thesis presents a probabilistic approach to transmission system assessment and expansion planning. The approaches have been implemented as a reliability tool using MATLAB and the results on sample systems are presented.

It has two portions. An optimal power flow based formulation is developed for first portion that determines the cost of Expected Energy Not Supplied. This formulation considers failure duration and frequency data, $\mathrm{N}-1$ contingencies and select $\mathrm{N}-2$ contingencies.

The second portion of the proposed tool presents a formulation that optimally plans for transmission system expansion. It considers three possibilities of both line and transformer upgrades (routine 1), only transmission line upgrades (routine 2) and only transformer upgrades

(routine 3). These propose cost of expansion that is compared with reduction of EENS costs. When the expansion costs are found to be lesser than reduction in EENS costs, there is net benefit from expansion plans and is proposed for adoption.

The proposed tool is tested on a sample 7-bus system, a 118-bus IEEE systems and a North American system. The tests reveal the benefit of the proposed method. The tests show that when the system has large values of EENS costs, expansion plans with technical and economic 
feasibility is possible.

\subsection{Contribution}

The aim of the study was to assess electric systems and find the optimum reinforcement approach to improve their reliability. In terms of assessment, load supply capability was the criteria chosen for analysis. The main contribution of the study was in the area of system reinforcement. When reinforcing operating power systems, designers must choose an aspect of the system to improve. System designers may be tasked with reinforcing the system to improve aspects such as voltage stability, power quality, energy transfer capacity, etc. Once the aspect is selected, a reinforcement approach must be chosen. This approach may involve addition of generating capacity, addition of shunt elements, increasing connection MVA ratings, etc. Load supply capability and increase of connection MVA ratings were chosen as the assessment criteria and reinforcement approach respectively, due to their common use in actual systems. Due to the complex nature of power systems and the various possible states and contingencies, system operators cannot take a straightforward deterministic approach when choosing which system connections to upgrade. For example, upgrading the MVA rating of a specific transmission line may prevent high amounts of load shedding in several contingencies, but these contingencies may have little to no probability of occurrence which would result in unnecessary investment. This thesis presented and implemented a new approach providing power system operators with the optimum system connections for upgrade to improve the load supply reliability of the system considering its probabilistic nature. 


\section{Appendix}

\section{IEEE 118 Bus System Data}

TABLE A1

118 SYSTEM BUS DATA

\begin{tabular}{|c|c|c|}
\hline $\begin{array}{l}\text { Bus } \\
\text { Number }\end{array}$ & Code & Voltage \\
\hline 1 & 2 & 0.955 \\
\hline 2 & 1 & 1 \\
\hline 3 & 1 & 1 \\
\hline 4 & 2 & 0.998 \\
\hline 5 & 1 & 1 \\
\hline 6 & 2 & 0.99 \\
\hline 7 & 1 & 1 \\
\hline 8 & 2 & 1.015 \\
\hline 9 & 1 & 1 \\
\hline 10 & 2 & 1.05 \\
\hline 11 & 1 & 1 \\
\hline 12 & 2 & \begin{tabular}{|l|l|}
0.99 \\
\end{tabular} \\
\hline 13 & 1 & 1 \\
\hline 14 & 1 & 1 \\
\hline 15 & 1 & \begin{tabular}{|l|}
0.97 \\
\end{tabular} \\
\hline 16 & 1 & 1 \\
\hline 17 & 1 & 1 \\
\hline 18 & 1 & 0.973 \\
\hline 19 & 1 & 0.962 \\
\hline 20 & 1 & 1 \\
\hline 21 & 1 & 1 \\
\hline 22 & 1 & 1 \\
\hline 23 & 1 & 1 \\
\hline 24 & 2 & 0.992 \\
\hline 25 & 2 & 1.05 \\
\hline 26 & 2 & 1.015 \\
\hline 27 & 1 & 0.968 \\
\hline 28 & 1 & 1 \\
\hline 29 & 1 & 1 \\
\hline 30 & 1 & 1 \\
\hline 31 & 1 & \begin{tabular}{|l|l|}
0.967 \\
\end{tabular} \\
\hline
\end{tabular}




\begin{tabular}{|c|c|c|}
\hline $\begin{array}{l}\text { Bus } \\
\text { Number }\end{array}$ & Code & Voltage \\
\hline 32 & 1 & 0.963 \\
\hline 33 & 1 & 1 \\
\hline 34 & 1 & 0.984 \\
\hline 35 & 1 & 1 \\
\hline 36 & 1 & 0.98 \\
\hline 37 & 1 & 1 \\
\hline 38 & 1 & 1 \\
\hline 39 & 1 & 1 \\
\hline 40 & 1 & 0.97 \\
\hline 41 & 1 & 1 \\
\hline 42 & 1 & 0.985 \\
\hline 43 & 1 & 1 \\
\hline 44 & 1 & 1 \\
\hline 45 & 1 & 1 \\
\hline 46 & 1 & 1.005 \\
\hline 47 & 1 & 1 \\
\hline 48 & 1 & 1 \\
\hline 49 & 1 & 1.025 \\
\hline 50 & 1 & 1 \\
\hline 51 & 1 & 1 \\
\hline 52 & 1 & 1 \\
\hline 53 & 1 & 1 \\
\hline 54 & 1 & 0.955 \\
\hline 55 & 1 & 0.952 \\
\hline 56 & 1 & 0.954 \\
\hline 57 & 1 & 1 \\
\hline 58 & 1 & 1 \\
\hline 59 & 1 & 0.985 \\
\hline 60 & 1 & 1 \\
\hline 61 & 2 & 0.995 \\
\hline 62 & 1 & 0.998 \\
\hline 63 & 1 & 1 \\
\hline 64 & 1 & 1 \\
\hline 65 & 2 & 1.005 \\
\hline 66 & 1 & 1.05 \\
\hline 67 & 1 & 1 \\
\hline 68 & 1 & 1 \\
\hline 69 & 3 & 1.035 \\
\hline 70 & 1 & 0.984 \\
\hline
\end{tabular}




\begin{tabular}{|c|c|c|}
\hline $\begin{array}{l}\text { Bus } \\
\text { Number }\end{array}$ & Code & Voltage \\
\hline 71 & 1 & 1 \\
\hline 72 & 2 & 0.98 \\
\hline 73 & 2 & 0.991 \\
\hline 74 & 1 & 0.958 \\
\hline 75 & 1 & 1 \\
\hline 76 & 1 & \begin{tabular}{|l|}
0.943 \\
\end{tabular} \\
\hline 77 & 1 & 1.006 \\
\hline 78 & 1 & 1 \\
\hline 79 & 1 & 1 \\
\hline 80 & 1 & 1.04 \\
\hline 81 & 1 & 1 \\
\hline 82 & 1 & 1 \\
\hline 83 & 1 & 1 \\
\hline 84 & 1 & 1 \\
\hline 85 & 1 & 0.985 \\
\hline 86 & 1 & 1 \\
\hline 87 & 2 & 1.015 \\
\hline 88 & 1 & 1 \\
\hline 89 & 2 & 1.005 \\
\hline 90 & 1 & 0.985 \\
\hline 91 & 2 & 0.98 \\
\hline 92 & 1 & 0.99 \\
\hline 93 & 1 & 1 \\
\hline 94 & 1 & 1 \\
\hline 95 & 1 & 1 \\
\hline 96 & 1 & 1 \\
\hline 97 & 1 & 1 \\
\hline 98 & 1 & 1 \\
\hline 99 & 2 & 1.01 \\
\hline 100 & 1 & 1.017 \\
\hline 101 & 1 & 1 \\
\hline 102 & 1 & 1 \\
\hline 103 & 1 & 1.01 \\
\hline 104 & 1 & 0.971 \\
\hline 105 & 1 & 0.965 \\
\hline 106 & 1 & 1 \\
\hline 107 & 1 & 0.952 \\
\hline 108 & 1 & 1 \\
\hline 109 & 1 & 1 \\
\hline
\end{tabular}




\begin{tabular}{|l|l|l|}
\hline $\begin{array}{l}\text { Bus } \\
\text { Number }\end{array}$ & Code & Voltage \\
\hline 110 & 1 & 0.973 \\
\hline 111 & 2 & 0.98 \\
\hline 112 & 1 & 0.975 \\
\hline 113 & 2 & 0.993 \\
\hline 114 & 1 & 1 \\
\hline 115 & 1 & 1 \\
\hline 116 & 2 & 1.005 \\
\hline 117 & 1 & 1 \\
\hline 118 & 1 & 1 \\
\hline
\end{tabular}

TABLE A2

118 SYSTEM LOAD DATA

\begin{tabular}{|l|l|l|}
\hline $\begin{array}{l}\text { Bus } \\
\text { Number }\end{array}$ & PL (MW) & QL (Mvar) \\
\hline 1 & 51 & 27 \\
\hline 2 & 20 & 9 \\
\hline 3 & 39 & 10 \\
\hline 4 & 30 & 12 \\
\hline 6 & 52 & 22 \\
\hline 7 & 19 & 2 \\
\hline 11 & 70 & 23 \\
\hline 12 & 47 & 10 \\
\hline 13 & 34 & 16 \\
\hline 14 & 14 & 1 \\
\hline 15 & 90 & 30 \\
\hline 16 & 25 & 10 \\
\hline 17 & 11 & 3 \\
\hline 18 & 60 & 34 \\
\hline 19 & 45 & 25 \\
\hline 20 & 18 & 3 \\
\hline 21 & 14 & 8 \\
\hline 22 & 10 & 5 \\
\hline 23 & 7 & 3 \\
\hline 27 & 62 & 13 \\
\hline 28 & 17 & 7 \\
\hline 29 & 24 & 4 \\
\hline 31 & 43 & 27 \\
\hline & & \\
\hline
\end{tabular}




\begin{tabular}{|c|c|c|}
\hline $\begin{array}{l}\text { Bus } \\
\text { Number }\end{array}$ & PL (MW) & QL (Mvar) \\
\hline 32 & 59 & 23 \\
\hline 33 & 23 & 9 \\
\hline 34 & 59 & 26 \\
\hline 35 & 33 & 9 \\
\hline 36 & 31 & 17 \\
\hline 39 & 27 & 11 \\
\hline 40 & 20 & 23 \\
\hline 41 & 37 & 10 \\
\hline 42 & 37 & 23 \\
\hline 43 & 18 & 7 \\
\hline 44 & 16 & 8 \\
\hline 45 & 53 & 22 \\
\hline 46 & 28 & 10 \\
\hline 47 & 34 & 0 \\
\hline 48 & 20 & 11 \\
\hline 49 & 87 & 30 \\
\hline 50 & 17 & 4 \\
\hline 51 & 17 & 8 \\
\hline 52 & 18 & 5 \\
\hline 53 & 23 & 11 \\
\hline 54 & 113 & 32 \\
\hline 55 & 63 & 22 \\
\hline 56 & 84 & 18 \\
\hline 57 & 12 & 3 \\
\hline 58 & 12 & 3 \\
\hline 59 & 277 & 113 \\
\hline 60 & 78 & 3 \\
\hline 62 & 77 & 14 \\
\hline 66 & 39 & 18 \\
\hline 67 & 28 & 7 \\
\hline 70 & 66 & 20 \\
\hline 74 & 68 & 27 \\
\hline 75 & 47 & 11 \\
\hline 76 & 68 & 36 \\
\hline 77 & 61 & 28 \\
\hline 78 & 71 & 26 \\
\hline 79 & 39 & 32 \\
\hline 80 & 130 & 26 \\
\hline 82 & 54 & 27 \\
\hline
\end{tabular}




\begin{tabular}{|c|c|c|}
\hline $\begin{array}{l}\text { Bus } \\
\text { Number }\end{array}$ & PL (MW) & QL (Mvar) \\
\hline 83 & 20 & 10 \\
\hline 84 & 11 & 7 \\
\hline 85 & 24 & 15 \\
\hline 86 & 21 & 10 \\
\hline 88 & 48 & 10 \\
\hline 90 & 78 & 42 \\
\hline 92 & 65 & 10 \\
\hline 93 & 12 & 7 \\
\hline 94 & 30 & 16 \\
\hline 95 & 42 & 31 \\
\hline 96 & 38 & 15 \\
\hline 97 & 15 & 9 \\
\hline 98 & 34 & 8 \\
\hline 100 & 37 & 18 \\
\hline 101 & 22 & 15 \\
\hline 102 & 5 & 3 \\
\hline 103 & 23 & 16 \\
\hline 104 & 38 & 25 \\
\hline 105 & 31 & 26 \\
\hline 106 & 43 & 16 \\
\hline 107 & 28 & 12 \\
\hline 108 & 2 & 1 \\
\hline 109 & 8 & 3 \\
\hline 110 & 39 & 30 \\
\hline 112 & 25 & 13 \\
\hline 114 & 8 & 3 \\
\hline 115 & 22 & 7 \\
\hline 117 & 20 & 8 \\
\hline 118 & 33 & 15 \\
\hline
\end{tabular}

\section{TABLE A3}

118 SYSTEM GENERATION DATA

\begin{tabular}{|c|c|c|c|}
\hline $\begin{array}{l}\text { Bus } \\
\text { Number }\end{array}$ & $\begin{array}{l}\mathrm{PG} \\
(\mathrm{MW})\end{array}$ & $\begin{array}{ll}\mathrm{QG} & \max \\
(\text { Mvar) } & \\
\end{array}$ & \begin{tabular}{|ll} 
QG & $\min$ \\
$($ Mvar)
\end{tabular} \\
\hline 1 & 0 & 15 & -5 \\
\hline 4 & -9 & 300 & -300 \\
\hline 6 & 0 & 50 & -13 \\
\hline
\end{tabular}




\begin{tabular}{|c|c|c|c|}
\hline $\begin{array}{l}\text { Bus } \\
\text { Number }\end{array}$ & $\begin{array}{l}\text { PG } \\
(\mathrm{MW})\end{array}$ & $\begin{array}{ll}\begin{array}{l}\text { QG } \\
\text { (Mvar) }\end{array} & \text { max } \\
\end{array}$ & $\begin{array}{ll}\begin{array}{l}\text { QG } \\
\text { (Mvar) }\end{array} & \text { min }\end{array}$ \\
\hline 8 & -28 & 300 & -300 \\
\hline 10 & 450 & 200 & -147 \\
\hline 12 & 85 & 120 & -35 \\
\hline 15 & 0 & 30 & -10 \\
\hline 18 & 0 & 50 & -16 \\
\hline 19 & 0 & 24 & -8 \\
\hline 24 & -13 & 300 & -300 \\
\hline 25 & 220 & 140 & -47 \\
\hline 26 & 314 & 1000 & -1000 \\
\hline 27 & -9 & 300 & -300 \\
\hline 31 & 7 & 300 & -300 \\
\hline 32 & 0 & 42 & -14 \\
\hline 34 & 0 & 24 & -8 \\
\hline 36 & 0 & 24 & -8 \\
\hline 40 & -46 & 300 & -300 \\
\hline 42 & -59 & 300 & -300 \\
\hline 46 & 19 & 100 & -100 \\
\hline 49 & 204 & 210 & -85 \\
\hline 54 & 48 & 300 & -300 \\
\hline 55 & 0 & 23 & -8 \\
\hline 56 & 0 & 15 & -8 \\
\hline 59 & 155 & 180 & -60 \\
\hline 61 & 160 & 300 & -100 \\
\hline 62 & 0 & 20 & -20 \\
\hline 65 & 391 & 200 & -67 \\
\hline 66 & 392 & 200 & -67 \\
\hline 70 & 0 & 32 & -10 \\
\hline 72 & -12 & 100 & -100 \\
\hline 73 & -6 & 100 & -100 \\
\hline 74 & 0 & 9 & -6 \\
\hline 76 & 0 & 23 & -8 \\
\hline 77 & 0 & 70 & -20 \\
\hline 80 & 477 & 280 & -165 \\
\hline 85 & 0 & 23 & -8 \\
\hline 87 & 4 & 1000 & -100 \\
\hline 89 & 607 & 300 & -210 \\
\hline 90 & -85 & 300 & -300 \\
\hline 91 & -10 & 100 & -100 \\
\hline 92 & 0 & 9 & -3 \\
\hline
\end{tabular}




\begin{tabular}{|l|l|l|l|}
\hline $\begin{array}{l}\text { Bus } \\
\text { Number }\end{array}$ & $\begin{array}{l}\text { PG } \\
\text { (MW) }\end{array}$ & $\begin{array}{l}\text { QG max } \\
\text { (Mvar) }\end{array}$ & $\begin{array}{l}\text { QG min } \\
\text { (Mvar) }\end{array}$ \\
\hline 99 & -42 & 100 & -100 \\
\hline 100 & 252 & 155 & -50 \\
\hline 103 & 40 & 40 & -15 \\
\hline 104 & 0 & 23 & -8 \\
\hline 105 & 0 & 23 & -8 \\
\hline 107 & -22 & 200 & -200 \\
\hline 110 & 0 & 23 & -8 \\
\hline 111 & 36 & 1000 & -100 \\
\hline 112 & -43 & 1000 & -100 \\
\hline 113 & -6 & 200 & -100 \\
\hline 116 & -184 & 1000 & -1000 \\
\hline
\end{tabular}

TABLE A4

118 SYSTEM BRANCH DATA

\begin{tabular}{|c|c|c|c|c|}
\hline $\begin{array}{ll}\text { From } & \text { Bus } \\
\text { Number } & \\
\end{array}$ & $\begin{array}{l}\text { To Bus } \\
\text { Number }\end{array}$ & $\begin{array}{l}\text { Line } R \\
(\mathrm{pu})\end{array}$ & $\begin{array}{l}\text { Line } X \\
(\mathrm{pu})\end{array}$ & $\begin{array}{l}\text { Charging } \\
(\mathrm{pu})\end{array}$ \\
\hline 1 & 2 & 0.0303 & 0.0999 & 0.0254 \\
\hline 1 & 3 & 0.0129 & 0.0424 & 0.01082 \\
\hline 4 & 5 & 0.00176 & 0.00798 & 0.0021 \\
\hline 3 & 5 & 0.0241 & 0.108 & 0.0284 \\
\hline 5 & 6 & 0.0119 & 0.054 & 0.01426 \\
\hline 6 & 7 & 0.00459 & 0.0208 & 0.0055 \\
\hline 8 & 9 & 0.00244 & 0.0305 & 1.162 \\
\hline 9 & 10 & 0.00258 & 0.0322 & 1.23 \\
\hline 4 & 11 & 0.0209 & 0.0688 & 0.01748 \\
\hline 5 & 11 & 0.0203 & 0.0682 & 0.01738 \\
\hline 11 & 12 & 0.00595 & 0.0196 & 0.00502 \\
\hline 2 & 12 & 0.0187 & 0.0616 & 0.01572 \\
\hline 3 & 12 & 0.0484 & 0.16 & 0.0406 \\
\hline 7 & 12 & 0.00862 & 0.034 & 0.00874 \\
\hline 11 & 13 & 0.02225 & 0.0731 & 0.01876 \\
\hline 12 & 14 & 0.0215 & 0.0707 & 0.01816 \\
\hline 13 & 15 & 0.0744 & 0.2444 & 0.06268 \\
\hline 14 & 15 & 0.0595 & 0.195 & 0.0502 \\
\hline 12 & 16 & 0.0212 & 0.0834 & 0.0214 \\
\hline 15 & 17 & 0.0132 & 0.0437 & 0.0444 \\
\hline 16 & 17 & 0.0454 & 0.1801 & 0.0466 \\
\hline
\end{tabular}




\begin{tabular}{|c|c|c|c|c|}
\hline $\begin{array}{ll}\text { From } & \text { Bus } \\
\text { Number } & \end{array}$ & $\begin{array}{l}\text { To Bus } \\
\text { Number }\end{array}$ & \begin{tabular}{|ll} 
Line & $R$ \\
$(\mathrm{pu})$
\end{tabular} & \begin{tabular}{ll|} 
Line & $X$ \\
$(\mathrm{pu})$
\end{tabular} & $\begin{array}{l}\text { Charging } \\
\text { (pu) }\end{array}$ \\
\hline 17 & 18 & 0.0123 & 0.0505 & 0.01298 \\
\hline 18 & 19 & 0.01119 & 0.0493 & 0.01142 \\
\hline 19 & 20 & 0.0252 & 0.117 & 0.0298 \\
\hline 15 & 19 & 0.012 & 0.0394 & 0.0101 \\
\hline 20 & 21 & 0.0183 & 0.0849 & 0.0216 \\
\hline 21 & 22 & 0.0209 & 0.097 & 0.0246 \\
\hline 22 & 23 & 0.0342 & 0.159 & 0.0404 \\
\hline 23 & 24 & 0.0135 & 0.0492 & 0.0498 \\
\hline 23 & 25 & 0.0156 & 0.08 & 0.0864 \\
\hline 25 & 27 & 0.0318 & 0.163 & 0.1764 \\
\hline 27 & 28 & \begin{tabular}{|l|}
0.01913 \\
\end{tabular} & 0.0855 & 0.0216 \\
\hline 28 & 29 & 0.0237 & 0.0943 & 0.0238 \\
\hline 8 & 30 & 0.00431 & 0.0504 & 0.514 \\
\hline 26 & 30 & 0.00799 & 0.086 & 0.908 \\
\hline 17 & 31 & 0.0474 & 0.1563 & 0.0399 \\
\hline 29 & 31 & 0.0108 & 0.0331 & 0.0083 \\
\hline 23 & 32 & 0.0317 & 0.1153 & 0.1173 \\
\hline 31 & 32 & 0.0298 & 0.0985 & 0.0251 \\
\hline 27 & 32 & 0.0229 & 0.0755 & 0.01926 \\
\hline 15 & 33 & 0.038 & 0.1244 & 0.03194 \\
\hline 19 & 34 & 0.0752 & 0.247 & 0.0632 \\
\hline 35 & 36 & 0.00224 & 0.0102 & 0.00268 \\
\hline 35 & 37 & 0.011 & 0.0497 & 0.01318 \\
\hline 33 & 37 & 0.0415 & 0.142 & 0.0366 \\
\hline 34 & 36 & \begin{tabular}{|l|}
0.00871 \\
\end{tabular} & 0.0268 & 0.00568 \\
\hline 34 & 37 & 0.00256 & 0.0094 & 0.00984 \\
\hline 37 & 39 & 0.0321 & 0.106 & 0.027 \\
\hline 37 & 40 & 0.0593 & 0.168 & 0.042 \\
\hline 30 & 38 & 0.00464 & 0.054 & 0.422 \\
\hline 39 & 40 & 0.0184 & 0.0605 & 0.01552 \\
\hline 40 & 41 & 0.0145 & 0.0487 & 0.01222 \\
\hline 40 & 42 & 0.0555 & 0.183 & 0.0466 \\
\hline 41 & 42 & 0.041 & 0.135 & 0.0344 \\
\hline 43 & 44 & 0.0608 & 0.2454 & 0.06068 \\
\hline 34 & 43 & 0.0413 & 0.1681 & 0.04226 \\
\hline 44 & 45 & 0.0224 & 0.0901 & 0.0224 \\
\hline 45 & 46 & 0.04 & 0.1356 & 0.0332 \\
\hline 46 & 47 & 0.038 & 0.127 & 0.0316 \\
\hline 46 & 48 & 0.0601 & 0.189 & 0.0472 \\
\hline
\end{tabular}




\begin{tabular}{|c|c|c|c|c|}
\hline $\begin{array}{ll}\text { From } & \text { Bus } \\
\text { Number } & \end{array}$ & $\begin{array}{l}\text { To Bus } \\
\text { Number }\end{array}$ & $\begin{array}{ll}\text { Line } & R \\
(\mathrm{pu}) & \end{array}$ & $\begin{array}{ll}\text { Line } & X \\
(\mathrm{pu}) & \end{array}$ & $\begin{array}{l}\text { Charging } \\
(\mathrm{pu})\end{array}$ \\
\hline 47 & 49 & 0.0191 & 0.0625 & 0.01604 \\
\hline 42 & 49 & 0.0715 & 0.323 & 0.086 \\
\hline 42 & 49 & 0.0715 & 0.323 & 0.086 \\
\hline 45 & 49 & 0.0684 & 0.186 & 0.0444 \\
\hline 48 & 49 & 0.0179 & 0.0505 & 0.01258 \\
\hline 49 & 50 & 0.0267 & 0.0752 & 0.01874 \\
\hline 49 & 51 & 0.0486 & 0.137 & 0.0342 \\
\hline 51 & 52 & 0.0203 & 0.0588 & 0.01396 \\
\hline 52 & 53 & 0.0405 & 0.1635 & 0.04058 \\
\hline 53 & 54 & 0.0263 & 0.122 & 0.031 \\
\hline 49 & 54 & 0.073 & 0.289 & 0.0738 \\
\hline 49 & 54 & 0.0869 & 0.291 & 0.073 \\
\hline 54 & 55 & 0.0169 & 0.0707 & 0.0202 \\
\hline 54 & 56 & 0.00275 & 0.00955 & 0.00732 \\
\hline 55 & 56 & 0.00488 & 0.0151 & 0.00374 \\
\hline 56 & 57 & 0.0343 & 0.0966 & 0.0242 \\
\hline 50 & 57 & 0.0474 & 0.134 & 0.0332 \\
\hline 56 & 58 & 0.0343 & 0.0966 & 0.0242 \\
\hline 51 & 58 & 0.0255 & 0.0719 & 0.01788 \\
\hline 54 & 59 & 0.0503 & 0.2293 & 0.0598 \\
\hline 56 & 59 & 0.0825 & 0.251 & 0.0569 \\
\hline 56 & 59 & 0.0803 & 0.239 & 0.0536 \\
\hline 55 & 59 & 0.04739 & 0.2158 & 0.05646 \\
\hline 59 & 60 & 0.0317 & 0.145 & 0.0376 \\
\hline 59 & 61 & 0.0328 & 0.15 & 0.0388 \\
\hline 60 & 61 & 0.00264 & 0.0135 & 0.01456 \\
\hline 60 & 62 & 0.0123 & 0.0561 & 0.01468 \\
\hline 61 & 62 & 0.00824 & 0.0376 & 0.0098 \\
\hline 63 & 64 & 0.00172 & 0.02 & 0.216 \\
\hline 38 & 65 & 0.00901 & 0.0986 & 1.046 \\
\hline 64 & 65 & 0.00269 & 0.0302 & 0.38 \\
\hline 49 & 66 & 0.018 & 0.0919 & 0.0248 \\
\hline 49 & 66 & 0.018 & 0.0919 & 0.0248 \\
\hline 62 & 66 & 0.0482 & 0.218 & 0.0578 \\
\hline 62 & 67 & 0.0258 & 0.117 & 0.031 \\
\hline 66 & 67 & 0.0224 & 0.1015 & 0.02682 \\
\hline 65 & 68 & 0.00138 & 0.016 & 0.638 \\
\hline 47 & 69 & 0.0844 & 0.2778 & 0.07092 \\
\hline 49 & 69 & 0.0985 & 0.324 & 0.0828 \\
\hline
\end{tabular}




\begin{tabular}{|c|c|c|c|c|}
\hline $\begin{array}{ll}\text { From } & \text { Bus } \\
\text { Number } & \end{array}$ & $\begin{array}{l}\text { To Bus } \\
\text { Number }\end{array}$ & $\begin{array}{ll}\text { Line } & R \\
(\mathrm{pu})\end{array}$ & $\begin{array}{l}\text { Line } X \\
(\mathrm{pu})\end{array}$ & $\begin{array}{l}\text { Charging } \\
\text { (pu) }\end{array}$ \\
\hline 69 & 70 & 0.03 & 0.127 & 0.122 \\
\hline 24 & 70 & 0.00221 & 0.4115 & 0.10198 \\
\hline 70 & 71 & 0.00882 & 0.0355 & 0.00878 \\
\hline 24 & 72 & 0.0488 & 0.196 & 0.0488 \\
\hline 71 & 72 & 0.0446 & 0.18 & 0.04444 \\
\hline 71 & 73 & 0.00866 & 0.0454 & 0.01178 \\
\hline 70 & 74 & 0.0401 & 0.1323 & 0.03368 \\
\hline 70 & 75 & 0.0428 & 0.141 & 0.036 \\
\hline 69 & 75 & 0.0405 & 0.122 & 0.124 \\
\hline 74 & 75 & 0.0123 & 0.0406 & 0.01034 \\
\hline 76 & 77 & 0.0444 & 0.148 & 0.0368 \\
\hline 69 & 77 & 0.0309 & 0.101 & 0.1038 \\
\hline 75 & 77 & 0.0601 & 0.1999 & 0.04978 \\
\hline 77 & 78 & 0.00376 & 0.0124 & 0.01264 \\
\hline 78 & 79 & 0.00546 & 0.0244 & 0.00648 \\
\hline 77 & 80 & 0.017 & 0.0485 & 0.0472 \\
\hline 77 & 80 & 0.0294 & 0.105 & 0.0228 \\
\hline 79 & 80 & 0.0156 & 0.0704 & 0.0187 \\
\hline 68 & 81 & 0.00175 & 0.0202 & 0.808 \\
\hline 77 & 82 & 0.0298 & 0.0853 & 0.08174 \\
\hline 82 & 83 & 0.0112 & 0.03665 & 0.03796 \\
\hline 83 & 84 & 0.0625 & 0.132 & 0.0258 \\
\hline 83 & 85 & 0.043 & 0.148 & 0.0348 \\
\hline 84 & 85 & 0.0302 & 0.0641 & 0.01234 \\
\hline 85 & 86 & 0.035 & 0.123 & 0.0276 \\
\hline 86 & 87 & 0.02828 & 0.2074 & 0.0445 \\
\hline 85 & 88 & 0.02 & 0.102 & 0.0276 \\
\hline 85 & 89 & 0.0239 & 0.173 & 0.047 \\
\hline 88 & 89 & 0.0139 & 0.0712 & 0.01934 \\
\hline 89 & 90 & 0.0518 & 0.188 & 0.0528 \\
\hline 89 & 90 & 0.0238 & 0.0997 & 0.106 \\
\hline 90 & 91 & 0.0254 & 0.0836 & 0.0214 \\
\hline 89 & 92 & 0.0099 & 0.0505 & 0.0548 \\
\hline 89 & 92 & 0.0393 & 0.1581 & 0.0414 \\
\hline 91 & 92 & 0.0387 & 0.1272 & 0.03268 \\
\hline 92 & 93 & 0.0258 & 0.0848 & 0.0218 \\
\hline 92 & 94 & 0.0481 & 0.158 & 0.0406 \\
\hline 93 & 94 & 0.0223 & 0.0732 & 0.01876 \\
\hline 94 & 95 & 0.0132 & 0.0434 & 0.0111 \\
\hline
\end{tabular}




\begin{tabular}{|c|c|c|c|c|}
\hline $\begin{array}{ll}\text { From } & \text { Bus } \\
\text { Number } & \end{array}$ & $\begin{array}{l}\text { To Bus } \\
\text { Number }\end{array}$ & \begin{tabular}{|l} 
Line $R$ \\
$(\mathrm{pu})$
\end{tabular} & \begin{tabular}{|l|} 
Line $X$ \\
$(\mathrm{pu})$
\end{tabular} & \begin{tabular}{|l} 
Charging \\
$(\mathrm{pu})$
\end{tabular} \\
\hline 80 & 96 & 0.0356 & 0.182 & 0.0494 \\
\hline 82 & 96 & 0.0162 & 0.053 & 0.0544 \\
\hline 94 & 96 & 0.0269 & \begin{tabular}{|l|}
0.0869 \\
\end{tabular} & \begin{tabular}{|l|l|}
0.023 \\
\end{tabular} \\
\hline 80 & 97 & 0.0183 & 0.0934 & 0.0254 \\
\hline 80 & 98 & 0.0238 & 0.108 & 0.0286 \\
\hline 80 & 99 & 0.0454 & 0.206 & 0.0546 \\
\hline 92 & 100 & 0.0648 & 0.295 & 0.0472 \\
\hline 94 & 100 & 0.0178 & 0.058 & 0.0604 \\
\hline 95 & 96 & 0.0171 & 0.0547 & 0.01474 \\
\hline 96 & 97 & 0.0173 & 0.0885 & 0.024 \\
\hline 98 & 100 & 0.0397 & 0.179 & \begin{tabular}{|l|}
0.0476 \\
\end{tabular} \\
\hline 99 & 100 & 0.018 & 0.0813 & 0.0216 \\
\hline 100 & 101 & 0.0277 & 0.1262 & 0.0328 \\
\hline 92 & 102 & 0.0123 & 0.0559 & \begin{tabular}{|l|}
0.01464 \\
\end{tabular} \\
\hline 101 & 102 & 0.0246 & 0.112 & 0.0294 \\
\hline 100 & 103 & 0.016 & 0.0525 & 0.0536 \\
\hline 100 & 104 & 0.0451 & 0.204 & 0.0541 \\
\hline 103 & 104 & 0.0466 & 0.1584 & 0.0407 \\
\hline 103 & 105 & 0.0535 & 0.1625 & 0.0408 \\
\hline 100 & 106 & 0.0605 & 0.229 & 0.062 \\
\hline 104 & 105 & \begin{tabular}{|l|}
0.00994 \\
\end{tabular} & 0.0378 & \begin{tabular}{|l|}
0.00986 \\
\end{tabular} \\
\hline 105 & 106 & 0.014 & 0.0547 & \begin{tabular}{|l|}
0.01434 \\
\end{tabular} \\
\hline 105 & 107 & 0.053 & 0.183 & 0.0472 \\
\hline 105 & 108 & 0.0261 & 0.0703 & 0.01844 \\
\hline 106 & 107 & 0.053 & 0.183 & 0.0472 \\
\hline 108 & 109 & 0.0105 & 0.0288 & 0.0076 \\
\hline 103 & 110 & \begin{tabular}{|l|}
0.03906 \\
\end{tabular} & 0.1813 & 0.0461 \\
\hline 109 & 110 & 0.0278 & 0.0762 & 0.0202 \\
\hline 110 & 111 & 0.022 & 0.0755 & 0.02 \\
\hline 110 & 112 & 0.0247 & 0.064 & 0.062 \\
\hline 17 & 113 & \begin{tabular}{|l|}
0.00913 \\
\end{tabular} & 0.0301 & \begin{tabular}{|l|}
0.00768 \\
\end{tabular} \\
\hline 32 & 113 & 0.0615 & 0.203 & 0.0518 \\
\hline 32 & 114 & 0.0135 & 0.0612 & 0.01628 \\
\hline 27 & 115 & 0.0164 & 0.0741 & 0.01972 \\
\hline 114 & 115 & 0.0023 & 0.0104 & 0.00276 \\
\hline 68 & 116 & 0.00034 & 0.00405 & 0.164 \\
\hline 12 & 117 & 0.0329 & 0.14 & 0.0358 \\
\hline 75 & 118 & 0.0145 & 0.0481 & \begin{tabular}{|l|}
0.01198 \\
\end{tabular} \\
\hline 76 & 118 & 0.0164 & 0.0544 & 0.01356 \\
\hline
\end{tabular}




\section{TABLE A5}

118 SYSTEM TRANSFORMER DATA

\begin{tabular}{|l|l|l|l|l|}
\hline $\begin{array}{l}\text { From } \\
\text { Number }\end{array}$ & $\begin{array}{l}\text { To Bus } \\
\text { Number }\end{array}$ & R $(\mathrm{pu})$ & $\mathrm{X}(\mathrm{pu})$ & Tap \\
\hline 8 & 5 & 0 & 0.0267 & 0.985 \\
\hline 26 & 25 & 0 & 0.0382 & 0.96 \\
\hline 30 & 17 & 0 & 0.0388 & 0.96 \\
\hline 38 & 37 & 0 & 0.0375 & 0.935 \\
\hline 63 & 59 & 0 & 0.0386 & 0.96 \\
\hline 64 & 61 & 0 & 0.0268 & 0.985 \\
\hline 65 & 66 & 0 & 0.037 & 0.935 \\
\hline 68 & 69 & 0 & 0.037 & 0.935 \\
\hline 81 & 80 & 0 & 0.037 & 0.935 \\
\hline
\end{tabular}




\section{Bibliography}

[1] A. Meier, Electric Power Systems: A Conceptual Introduction, Hoboken, NJ: Wiley-IEEE Press, 2006.

[2] Y. Ding et al, "Long-term reserve expansion of power systems with high wind power penetration using universal generating function methods," IEEE Trans. Power Syst., vol. 26, no. 2, pp. 766-774, May 2011.

[3] F. Saccomanno, Electric Power Systems: Analysis and Control, Hoboken, NJ: Wiley-IEEE Press, 2011.

[4] V.Z. Farahani and S. Jadid, "Assessment of restructured power systems security using Contingency Sensitivity Index," in $40^{\text {th }}$ North American Power Symp., Calgary, AB, 2008, pp.1-7.

[5] M. Nizam, et al., "Dynamic voltage collapse prediction on a practical power system using power transfer stability index," in Research and Development, 2007. SCOReD 2007. 5th Student Conference on, 2007, pp. 1-6.

[6] W. Li, Probabilistic Transmission System Planning, Hoboken, NJ: Wiley-IEEE Press, 2011.

[7] T. Mason, et al., "Capital costs for transmission and substation," Black and Veatch, Overland Park, KS, 2012.

[8] "1980-2010: Transmission lines data, analysis and trends over 30 years," Canadian Electricity Association, Ottawa, ON, 2010.

[9] “1980-2010: Transformer bank data, analysis and trends over 30 years," Canadian Electricity Association, Ottawa, ON, 2010.

[10] Ieee118cdf.txt, http://www.ee.washington.edu/research/pstca/ 
[11] W. Li and P. Choudhury, "Probabilistic planning of transmission systems: Why, how and an actual example," in 2008 IEEE Power and Energy Society General Meeting Conversion and Delivery of Electrical Energy in the 21st Century, Pittsburgh, PA, 2008, pp. 1-8.

[12] M. Sarfati et al., "Transmission planning with probabilistic modeling of multiple contingencies," in 2013 10th Int. Conf. European Energy Market (EEM), Stockholm, Sweden, 2013, pp. 1-6.

[13] D. Lei et al, "Research on transmission expansion planning based on probabilistic incremental reliability value," in 2011 Asia-Pacific Power and Energy Engineering Conf. (APPEEC), Wuhan, China, 2011, pp. 1-4.

[14] J. Choi et al, "Probabilistic reliability criterion for planning transmission system expansions," IEE Proc. Generation, Transmission Distribution, vol. 153, pp. 719-727, Nov. 2006.

[15] M. Lammintausta et al, "Transmission capacity assessment by using simple probabilistic planning," in 2003 IEEE Bologna Power Tech Conf Proc., Bologna, Italy, 2003.

[16] H. Mori and H. Kakuta, "A CNSGA-II based method for multi-objective probabilistic transmission network expansion planning," in 2010 IEEE Power and Energy Society General Meeting, Minneapolis, MN, 2010, pp. 1-6.

[17] W. Li et al, "Probabilistic reliability planning at British Columbia Transmission Corporation: method and project case," in Proc. 10th Int. Conf. Probabilistic Methods Applied to Power Systems, 2008. PMAPS '08, Rincon, Puerto Rico, 2008, pp. 1-7. 
[18] J. Choi et al, "Transmission system expansion planning considering expected stand-by cost based on probabilistic approach," in Power Systems Conf. Expo., 2006. PSCE '06. 2006 IEEE PES, Atlanta, GA, 2006, pp. 1498-1506.

[19] P. Zhang et al, "Utility application experience of probabilistic risk assessment method," in Power Systems Conf. and Expo., 2009. PSCE '09. IEEE/PES, Seattle, WA, 2009, pp. $1-7$.

[20] S. Beharrysingh and C. Sharma, "Development and application of a probabilistic simulation program for long term system planning," in Int. Conf. Probabilistic Methods Applied to Power Systems, 2006. PMAPS 2006., Stockholm, Sweden, 2006, pp. 1-9.

[21] J. Zhu, Optimization of Power System Operation, Hoboken, NJ: Wiley-IEEE Press, 2009.

[22] M. Adibi, Power System Restoration: Methodologies and Implementation Strategies, Hoboken, NJ: Wiley-IEEE Press, 2000.

[23] J. Momoh and L. Mili, Operation and Control of Electric Energy Processing Systems, Hoboken, NJ: Wiley-IEEE Press, 2010.

[24] M. V. Suganyadevia and C. K. Babulal, "Estimating of loadability margin of a power system by comparing voltage stability indices," in Proc. Int. Conf. Control, Automation, Communication and Energy Conservation, 2009 (INCACEC 2009), Perundurai, Tamilnadu, 2009, pp. 1-4. 